\title{
The morphology and internal structure of dogwood (Cornus L.) endocarps in the taxonomy and phylogeny of the genus
}

\author{
Maria Morozowska ${ }^{\text {Corresp., } 1}{ }^{1}$, Agata Woźnicka ${ }^{2}$, Renata Nowińska ${ }^{1}$ \\ ${ }^{1}$ Department of Botany, Faculty of Agronomy, Horticulture and Bioengineering, Poznań University of Life Sciences, Poznań, Poland \\ 2 ul. Radosna 94, Legnica, Poland \\ Corresponding Author: Maria Morozowska \\ Email address: maria.morozowska@up.poznan.pl
}

The genus Cornus is known for its complicated taxonomy and extreme polymorphism. Currently, dogwoods are classified into four morphological groups reflected in four phylogenetic clades: blue- or white-fruited dogwoods (BW), cornelian cherries (CC), bigbracted dogwoods (BB), and dwarf dogwoods (DW). The present study is a continuation of a series of papers that started with the examination of the endocarp morphological diversity among BW species. The endocarps of 22 Cornus species were studied according to their morphology, internal structure, and sculpture; the aim was to evaluate the taxonomic importance of the examined characters and check whether endocarp differentiation supports the published phylogenies, according to which the relationships within the genus are indicated as (BW(CC(DW-BB))). Among the quantitative characters, the endocarp's length, thickness, and width, its length/width ratio, and the number of vascular bundles on its surface were considered taxonomically important. Regarding the qualitative characters, the taxonomic significance of the stone shape, the endocarp apex and base outline, the position of vascular bundles on the endocarp surface, and the presence of the apical cavity and distinct furrow on the endocarp side walls was proved. Additionally, the uniform qualitative characters having a $100 \%$ share of a given character state were identified. Cornelian cherries and dwarf dogwoods were characterised by the presence of four uniform characters. In the big-bracted group, two uniform characters were found. Blue- or white-fruited species were the most heterogeneous, with no uniform characters. Regarding the endocarp's internal structure, the presence of secretory cavities in the endocarp wall and in the septa, the presence of crystals in the outer endocarp, the number of cell layers in the transition sclereid zone, and the primary and secondary sculptures were found to be taxonomically significant. Additionally, the comparative analyses of dogwood endocarps found the following parameters to be useful: the germination valve thickness, the ratio of endocarp wall thickness to endocarp diameter, and the septum's width and structure. Due to the great differentiation of the examined 
characters, it was difficult to verify the research hypothesis unambiguously. The calculated similarity coefficients of the endocarps' qualitative and quantitative characters revealed the highest morphological similarity of endocarps between DW and BB groups, supporting the phylogenetic relationships based on molecular evidence. The number of vascular bundles on the endocarp surface was the character that supported this similarity the most. The similarity coefficients calculated separately for qualitative characters showed the closest similarity between groups CC-DW. However, these results do not directly reflect any of the published phylogenies. 
1 The morphology and internal structure of dogwood (Cornus L.) endocarps in the taxonomy

2 and phylogeny of the genus

4 Maria Morozowska ${ }^{1}$, Agata Woźnicka $^{2}$, Renata Nowińska ${ }^{1}$

$5 \quad{ }^{1}$ Department of Botany, Faculty of Agronomy, Horticulture and Bioengineering, Poznań

6 University of Life Sciences, Poznań, Poland

72 ul. Radosna 94, Legnica, Poland

8

9 Corresponding Author:

10 Maria Morozowska ${ }^{1}$

11 Wojska Polskiego 71C, Poznań 60-625, Poland

12 Email address: maria.morozowska@up.poznan.pl

\section{Abstract}

The genus Cornus is known for its complicated taxonomy and extreme polymorphism. Currently, dogwoods are classified into four morphological groups reflected in four phylogenetic clades: blue- or white-fruited dogwoods (BW), cornelian cherries (CC), big-bracted dogwoods (BB), and dwarf dogwoods (DW). The present study is a continuation of a series of papers that started with the examination of the endocarp morphological diversity among BW species. The endocarps of 22 Cornus species were studied according to their morphology, internal structure, and sculpture; the aim was to evaluate the taxonomic importance of the examined characters and check whether endocarp differentiation supports the published phylogenies, according to which the relationships within the genus are indicated as $(\mathrm{BW}(\mathrm{CC}(\mathrm{DW}-\mathrm{BB})))$. Among the quantitative characters, the endocarp's length, thickness, and width, its length/width ratio, and the number of vascular bundles on its surface were considered taxonomically important. Regarding the qualitative characters, the taxonomic significance of the stone shape, the endocarp apex and base outline, the position of vascular bundles on the endocarp surface, and the presence of the apical cavity and distinct furrow on the endocarp side walls was proved. Additionally, the uniform qualitative characters having a $100 \%$ share of a given character state were identified. Cornelian cherries and dwarf dogwoods were characterised by the presence of four uniform characters. In the big-bracted group, two uniform characters were found. Blue- or white-fruited species were the most heterogeneous, with no uniform characters. Regarding the endocarp's internal structure, the presence of secretory cavities in the endocarp wall and in the septa, the presence of crystals in the outer endocarp, the 
34 number of cell layers in the transition sclereid zone, and the primary and secondary sculptures 35 were found to be taxonomically significant. Additionally, the comparative analyses of dogwood

36

37

38

39

40

41

42

43

44

45

46

47

48

49

50

51

52

53

54

55

56

57

58

59

60

61

62

63

64

endocarps found the following parameters to be useful: the germination valve thickness, the ratio of endocarp wall thickness to endocarp diameter, and the septum's width and structure. Due to the great differentiation of the examined characters, it was difficult to verify the research hypothesis unambiguously. The calculated similarity coefficients of the endocarps' qualitative and quantitative characters revealed the highest morphological similarity of endocarps between DW and $\mathrm{BB}$ groups, supporting the phylogenetic relationships based on molecular evidence. The number of vascular bundles on the endocarp surface was the character that supported this similarity the most. The similarity coefficients calculated separately for qualitative characters showed the closest similarity between groups CC-DW. However, these results do not directly reflect any of the published phylogenies.

Keywords: Fruit stones, micromorphology, SEM, sculpture, subgenera, species

\section{Introduction}

The monophyly of Cornus L. is strongly supported by morphological and molecular data (Murrell, 1993; Xiang et al., 1993, 1996, 1998; Fan \& Xiang 2001). However, due to the genus' extreme polymorphism, the relationships between different taxonomic units (subgenera, sections) into which the genus was divided in the past were unclear for almost a century (for details, see Xiang et al., 2006). The genus comprises approximately 60 species classified into 10 subgenera, which belong to four morphological groups: blue- or white-fruited dogwoods (BW) [Yinquania (Zhu) Murrell, Kraniopsis Raf., Mesomora Raf.], cornelian cherries (CC) [Afrocrania (Harms) Wangerin, Cornus L., Sinocornus Q. Y. Xiang], big-bracted dogwoods (BB) [Discocrania (Harms) Wangerin, Cynoxylon Raf., Syncarpea (Nakai) Xiang], and dwarf dogwoods (DW) (Arctocrania Endl. Ex Reichenbach). Similar to the morphological classification, four major clades-BW, $\mathrm{CC}, \mathrm{BB}$, and $\mathrm{DW}$ - have been identified within the genus, resulting from phylogenetic studies based on either morphological, molecular, or combined data (Xiang et al., 1996, 2006; Fan \& Xiang, 2001). However, the relationships of the particular groups, subgenera, or species based on the morphological or molecular evidence were incongruent (Murrell, 1993; Xiang et al., 2006).

Murrell (1993), through his cladistic analysis of 28 morphological, anatomical, chemical, and cytological characters, performed a simultaneous analysis of relationships within the genus

Peer) reviewing PDF | (2020:11:55179:2:0:NEW 10 Aug 2021) 
65

66

67

68

69

70

71

72

73

74

75

76

77

78

79

80

81

82

83

84

85

86

87

88

89

90

91

92

93

94

95

and generated a hypothesis on the Cornus phylogeny as (BW(DW(CC-BB))). Such hypothesis, in which the closest relationship was found between the $\mathrm{CC}$ and $\mathrm{BB}$ groups, differed to some extent from those proposed earlier (Adams, 1949; Bate-Smith et al., 1975; Jahne, 1986; Eyde, 1988).

However, this typology's unique feature was the placement of the dwarf dogwoods with subgenus Arctocrania as the sister group basal to the clade formed by the subgenera Afrocrania, Cornus, Discocrania, Cynoxylon, and Syncarpea (see Figs. 1 and 2 in Xiang et al., 2006). Subsequently, Xiang et al. (1998) and Fan \& Xiang (2001) showed the phylogenetic relationships between four clades within genus Cornus as (BW(CC(DW-BB ))). However, these relationships were supported by low bootstrap values, so they were not clearly resolved. According to Xiang et al. (2006), the differences between the molecular and morphological data arose because none of the previous molecular analyses included all ten subgenera of Cornus, and the samplings were limited. Furthermore, in Murrell's (1993) cladistic analysis of morphological characters, the chosen outgroup taxa were not complete as only the genera Mastixia and Diplopanax were taken into consideration. Xiang et al. (2006) generated DNA sequences for maturase K (matK) and internal transcribed spacer (ITS) with a complete sampling of species to reconstruct a species-level phylogeny of the genus. The authors reconsidered Murrell's (1993) morphological data matrix and expanded it by introducing nine new characters; they added the genus Alangium (sister of Cornus) as an outgroup. This provided improved resolution of the species' relationships. However, the relationships between subgenera and clades were still different depending on the type of the data considered. The results of the phylogenetic analyses of the morphological data suggested that the BB and CC groups were sisters, but they were only moderately supported by the bootstrap values. According to the relationships suggested by the molecular evidence, the mat $K$ trees showed that DW-BB and CC-BW were two pairs of sister clades, with the latter being weakly supported (65\%). In turn, the ITS trees placed the CC group with the BB-DW clade rather than with the BW group. The combined matK-ITS data set showed relationships similar to those of the matK and ITS trees but with higher support for most of the nodes. Complex analyses performed with the use of the combined results of phylogenetic and morphological studies, together with the already published $r b c L$ and $26 \mathrm{~S}$ rDNA sequences, resolved the relationships among clades as (BW(CC(DW-BB))) (Xiang et al., 2006).

The combined analyses of Xiang et al. (2006) included 37 morphological characters and all DNA sequences using parsimony and Bayesian methods. Most morphological characters 
96 included inflorescence and flower structure, leaves and locules, and the chromosome number and 97 selected chemical compounds. The stony endocarps, the reproductive structures of potentially high taxonomic value, were examined only within a limited range. Only three characters of endocarps were analysed: shape, cavities, and apex of the fruit stone. Recently, extensive studies on dogwoods' morphology, including their stony endocarps, were performed by Schulz $(2011,2012)$, Zieliński et al. (2014), and Woźnicka et al. (2015). Schulz (2011) gave an overview of the morphological differentiation within the genus, including the fruit stones' morphology, and discussed the various affinity of the particular groups and subgroups considering the Cornus genus' great polymorphism. In his next work, Schulz (2012) characterised the alternate-leafed dogwoods of the subgenera Mesomora and Kraniopsis (BW), including the cultivated taxa. The author stressed the importance of the endocarp morphology in the taxonomy of dogwoods and proposed a new taxonomic approach for some of the very closely related species, for example, $C$. alba L., C. sericea L. (= C. stolonifera Michx.), and C. occidentalis [(Torr. \& A. Gray) Coville]; C. amomum (Mill.) and C. obliqua (Raf.); C. australis (C. A. Mey) and C. sanguinea (L.); and C. foemina (Mill.) and C. racemose (Lam.). Taking into consideration the earlier suggestions of Wangerin (1910), Schulz (2012) proposed the rank of the subspecies within Cornus alba as follows: C. alba L. subsp. alba and C. alba subsp. stolonifera (Michx.). Later, Zieliński et al. (2014) summarised and described the history of C. alba and C. sericea taxonomy. The authors discussed the problems with the identification of these very similar and closely related species and agreed that the broad species concept of $C$. alba s.l. (including $C$. sericea) was most reliable. Justifying such a position, Zieliński et al. (2014) also stressed that wild plants in generative and vegetative states could be properly identified and that cultivars of uncertain origin could have an easier and less controversial classification.

Woźnicka et al. (2015), who described the qualitative and quantitative differences in the morphology of endocarps of 15 Cornus species from the BW group, proved the taxonomic and systematic importance of the endocarp morphology. However, their study couldn't fully explain species status in the case of closely related taxa, as some of the observed morphological differences overlapped or were too subtle. In the published dichotomous key based on the morphology of endocarps, Woźnicka et al. (2015) adopted the new taxonomic treatments of very closely related species proposed by Schulz (2012). The authors discussed the taxonomic importance and systematic implications of the obtained results in a phylogenetic framework. Further, a partial 
127 congruence between the observed morphological differentiation of endocarps and a currently 128 available species phylogeny within the BW clade of the genus Cornus was found.

129 Apart from the modern dogwoods, the well-preserved fruits and woody endocarps of the 130 extinct representatives of the Cornaceae family and the whole Cornales clade are by far the most 131 taxonomically informative fossils, which facilitate a better understanding of the initial 132 phylogenetic diversification of Cornales (Eyde, 1987, 1988; Manchester et al., 2010; Atkinson et 133 al., 2016; Stockey et al,. 2016; Atkinson et al., 2017). The present study continues a series of papers 134 that started with Woźnicka et al. (2015), who examined the diversity within endocarp morphology 135 among selected species from the blue- and white-fruited dogwoods. The present work focused on the morphology of fruit stones of 22 species representing the whole genus Cornus; it used the same methods employed by Woźnicka et al. (2015). Additionally, our present approach was extended to analyse the endocarps' sculpture and internal structure. The main aim of our study was to verify

the taxonomical importance of the examined characters. We also compiled the earlier and presently obtained results to discuss our findings in a broader context, considering the phylogenetic relationships within the entire Cornus genus. We hypothesised that the grouping of the studied dogwoods based on the endocarps' morphology and internal structure coincides with phylogenetic relationships $(\mathrm{BW}(\mathrm{CC}(\mathrm{DW}-\mathrm{BB})))$ based on the combined molecular and morphological data described by Xiang et al. (2006).

\section{Materials \& Methods}

146

\section{Materials}

Endocarps of 22 Cornus species representing four morphological groups (BW, CC, BB, and DW) were collected (Table 1). The selection of species depended only on their availability in botanical and herbarium collections. Initially, 27 species were selected for the study. Unfortunately, in the case of five species (C. volkensii Harms and C. chinensis Wangerin subg. Sinocornus, C. hongkongensis Hemsl subg. Syncarpea, C. oblonga Wall. subg. Yinquania, and C. disciflora Moc \& Sessé ex DC. subg. Discocrania), the obtained material was insufficient, so they were not included in the study. For the sources of endocarps of 15 blue- or white-fruited dogwoods, see Woźnicka et al. (2015). The stones of red-fruited Cornus species were collected from cultivated plants growing in 10 Polish and 8 other European, Asian, or American botanical collections (Supplemental Files 1 and 2) and from 12 herbarium collections: BM, BG1, G, GH, H, K, KOR, KRAM, L, POZ, S, TRN (Thiers, 2021) (Supplemental File 3). Plant materials were collected 
158 between 2009 and 2012, from July to October, during the fruiting period of individual species. The 159 endocarps were extracted from the fully developed ripened fruits.

160 The examination of the endocarp morphology was partly based on our earlier work; we 161 included in our analyses the results obtained by Woźnicka et al. (2015), who examined 2,812 162 stones collected from 185 specimens representing 15 dogwood species of the blue- or white-fruited 163 dogwoods from the BW group. Here we examined 1,034 stones collected from 69 specimens 164 representing seven red-fruited Cornus species of the CC, BB, and DW groups. The combined data 165 set of the endocarp morphology of 22 dogwood species representing all four groups (BW, CC, BB, 166 and DW) was used for the complex analysis based on the results of morphological measurements 167 of 3,846 stones collected from 254 specimens. Each species was represented by 3-15 specimens 168 derived either from the herbarium or cultivated collections. Within these collected materials, 2-30 169 stones per specimen were evaluated depending on their availability. Details are provided in Supplemental File 4.

Within 22 species of dogwoods, the internal structures of 317 stones were examined. The number of tested endocarps per species depended on their availability. For most species, 15 endocarps each were tested. The exceptions were C. nuttallii and C. suecica, each with 10 endocarps tested, and C. canadensis, with 12 endocarps tested.

The original nomenclature of the examined dogwoods was considered appropriate and reliable. However, to increase the reliability of the study, approximately $70 \%$ of the specimens were verified according to their morphology (Supplemental Files 2 and 3). The nomenclature of the examined species follows The Plant List, version 1.1 (2013). The specimens and fruit materials were deposited in the herbarium of the Department of Botany (POZNB) at Poznan University of Life Sciences in Poland.

\section{Plant measurements}

\section{Endocarp morphology}

The seventeen morphological characters (eight qualitative and nine quantitative) of the woody stones were analysed (Table 2) for 3,846 stones collected. The terminology used to describe these 17 morphological characters of endocarps was from Woźnicka et al. (2015, Table 2 and Fig. 3). Since few of endocarps' qualitative characters (ASH, apical shape; $\mathrm{BSH}$, basal shape; $\mathrm{SSH}$, shape in the vertical projection; and VBP, position of vascular bundles on the surface) were 
189 was determined for each species under study (Supplemental File 5). If the share of a given state 190 was $100 \%$ of the occurrences, the character was regarded as uniform for the group, subgenera, or 191 species. If the share of a character state was greater than or equal to $90 \%$, it was regarded as typical 192 for these taxa.

\section{Endocarp cross-section}

194 Four quantitative characters of the endocarp structure visible on the endocarp equatorial 195 cross-section were analysed (Table 3, Fig. 1) for 317 stones. Longitudinal sections of the stones were also submitted for scanning electron microscopy (SEM). The endocarps were sectioned with 197 a Leica CM18050 cryostat in a cryochamber at $-15^{\circ} \mathrm{C}$. The ImageJ application (Rasband 1997-

198

199

200

201

202

203

204

205

206

207

208

209

210

211

212

213

214

215

216

217

218

219 2018) was used for measurements. A Zeiss Axioscope A1 stereoscopic microscope was used for photographic documentation.

\section{Data analysis}

\section{Endocarp morphology}

The comparative analyses of the results were made at three levels: groups $(\mathrm{BW}, \mathrm{CC}, \mathrm{DW}$, and BB), subgenera (Kraniopsis, Mesomora, Cornus, Cynoxylon, Syncarpea, and Arctocrania), and species.

The statistical analyses were based on the average values of the measurements of 17 morphological characters obtained from 254 specimens considered in the present work. The quantitative characters of the stones were transformed logarithmically to obtain a normal or close to normal data distribution for statistical purposes (Sárnal et al., 1999; Howell, 2007; Tabachnick \& Fidell, 2007).

The principal component analysis (PCA) aimed to estimate the diversity of specimens in terms of the quantitative morphological characters, identify the main trends in the diversity of the set of specimens, and select the quantitative characters that were most closely related to the observed gradient of diversity. The PCA was used for all quantitative characters, including apical cavity length (ACL) and width (ACW). The apical cavity was present in 12 out of 22 species and was a constant character only in three of them. Using PCA allowed us to determine whether such very strongly variable characters have a significant influence on the differentiation of the Cornus genus. If endocarps had no apical cavity, zero was entered for ACL and ACW. First, all data were standardised due to the wide range of values. The calculations were based on the characters' correlation matrix and varimax rotation. The Kaiser criterion was used to select the principal 
220 221

222

223 224 225 226 227 228 229 230 231 232 233 234 235 236 237 238 239 240 241 242 243 244 245 246 247 248 249 250

components (V) that significantly explained the variability of the set. Therefore, the principal components whose eigenvalue exceeded or was close to 1.0 were left. The PCA enabled the identification of the characters strongly correlated $(r \geq 0.60)$ with previously selected principal components.

The multivariate analyses of variance (MANOVAs) based on the three PC scores were carried out to determine whether a separation of endocarps in terms of their belonging to groups, subgenera, and species was statistically significant. To evaluate this differentiation, each PC axis was compared using analyses of variance (ANOVAs) with the Bonferroni correction.

At the next stage of statistical analysis, the specimens from particular groups, subgenera, and species were assessed for significant differences in the morphological characters selected through the PCA method. The homogeneity of variances of characters was checked with Levene's test. As some of the characters did not meet the assumption of the homogeneity of variance, the significance of differences was verified using one-way ANOVA with the Welch correction and Dunnett's T3 post-hoc test.

The statistical analyses of the eight qualitative characters were based on individual measurements of 3,846 stones. Chi-square tests of independence were used to test the relationship between specific qualitative characters and the belonging of the dogwood specimens to particular groups, subgenera, and species. The Yates correction was used in the analyses with one degree of freedom $(d f=1)$. With this correction, the discrete distribution of the characters was better approximated by the continuous chi-square distribution (Aczel, 2000). When the expected value was less than 5 , the closest states of the characters were combined into one class (in tests with $d f$ $>1$ ), or Fisher's exact test was used (in tests with $d f=1$ ).

42 To check whether the studied morphological characters of the endocarps reflected the current relations within the Cornus genus (Murrell, 1993; Xiang et al., 2006), similarity coefficients were calculated. For eight log-transformed quantitative characters (one character was excluded during the course of analyses; see Results), the Manhattan distance converted into similarity was calculated. In the case of eight qualitative characters, the Jaccard similarity coefficient was used. The qualitative characters were common in several states, and the same character states were often observed in the four compared groups of dogwood. Therefore, the similarities between the groups concerned a similar frequency of occurrence of character states. For this reason, when calculating the Jaccard index, the number of endocarps sharing the same 
251 character states was considered as the intersection for each pair and was divided by the total 252 remaining number of endocarps for that pair. For both quantitative and qualitative characters, 253 Gower's similarity coefficient was developed. The obtained similarity coefficients were in the 254 range [0 1], with 1 denoting the highest similarity (the compared groups were identical) and 0 255 denoting the lowest.

256 Most statistical analyses were performed using the program STATISTICA 11 (StatSoft, 257 Poland). ANOVAs with Welch's correction and Dunnett's T3 tests were calculated with IBM 258 SPPS 21.0 (SPSS Inc., Chicago, IL, USA). The Bonferroni correction was found at $259 \mathrm{http} / /$ quantitativeskills.com/sisa/calculations/bonfer.htm. The chi-square tests of independence 260 with $d f>1$ were performed at http://www.quantpsy.org/chisq/chisq.htm.

\section{Endocarp cross-section}

262

The discriminant function analysis (DFA) was used to check which of the species under

263 study were the most strongly discriminated on the basis of three examined characters of the

264 265

266

267

268

269

270

271

272

273

274

275

276

277

278

279

280

281 endocarps present in all groups studied (GVT, germination valve thickness; SMW, septum width; and WTP, thickness of the endocarp wall divided by the endocarp diameter or multiplied by 100). Factor structure coefficients, that is, simple correlations between the characters and discriminatory axes were used. Each character was tested statistically to verify the initial assessment of diversity obtained through the DFA. Some of the data did not have a normal distribution after the logarithmic transformation either. Therefore, nonparametric tests were used on nontransformed data. The Kruskal-Wallis $H$ test was used for three combinations of categories (22 species, 4 groups, 6 subgenera). Numerous Mann-Whitney $U$ tests were also conducted to compare consecutive pairs within each category. Statistical analyses were performed using STATISTICA 11 (StatSoft, Poland).

\section{SEM analysis}

Endocarp cross-sections and longitudinal sections were made at half of the endocarps' lengths or widths, respectively. Whole endocarps and their cuttings were gold-coated and examined with a Zeiss EVO 40 electron microscope. The following surface micromorphological characters were examined: cellular pattern, cell outline (tetragonal, polygonal, rounded, irregular), anticlinal walls (straight, sinuate), relief of the anticlinal cell boundary (raised, channelled), and curvature of the outer periclinal cell wall (concave, convex, flat). According to endocarps' internal structure, the following characters were examined: the outer endocarp (OE) (absent, present), the 
282 type of sclereids in the OE (isodiametric, elongated), crystals in the OE (absent, present), the inner 283 endocarp (IE) (absent, present), the transitional sclereid zone (TS) (absent, present/the number of 284 cell layers), the structure of the endocarp septum (S) (solid, openwork, partly openwork), and 285 crystals in $\mathrm{S}$ (absent, present).

\section{Results}

287 Endocarp morphology

\section{Quantitative characters}

The diversity of the quantitative morphological characters was initially tested using PCA. 290 The first three principal components together explained $77.95 \%$ of the total variance $(\mathrm{V} 1=$ $29135.08 \% ; \mathrm{V} 2=31.98 \% ; \mathrm{V} 3=14.74 \%$ ). The scatter diagram of the first two components showed a 292 clear cluster of specimens belonging to the same species and those belonging to the same subgenus 293 and group (Fig. 2). The groups and subgenera were clearly separated, with the exception of the CC 294 group and the Cynoxylon subgenus from the BB group, which overlapped. The first principal component mostly separated the DW and CC groups (Table 4). Four characters were negatively correlated with the first principal component: the endocarp thickness (ST), the apical cavity width $(\mathrm{ACW})$, the apical cavity length (ACL), and the endocarp width (SW) (Table 5). The second component separates the above-mentioned groups from the species included in the BW group. The following characters were negatively correlated with the second component: the endocarp length (SL) and the endocarp length-to-width ratio (SL/SW). The following characters were positively

301

302

303

304

305

306

307

308

309

310

311

312 correlated: the share of bifurcated vascular bundles (FV\%) and the number of vascular bundles on the endocarp surface (VN). The third principal component noticeably separated the BB and DW groups (Table 4). The following characters were positively correlated: the apical cavity width $(\mathrm{ACW})$ and the apical cavity length (ACL). The endocarp width-to-thickness ratio (SW/ST) was not significantly correlated with any of the principal components (Table 5). Therefore, this character was not included in further analyses.

MANOVAs based on PC scores (V1-V3), with the taxonomic affiliations as independent variables, confirmed that tested groups, subgenera, and species differed in the quantitative characters of endocarps (groups: Wilks' lambda $=0.03, F_{(3,9)}=203.67, P<0.0001$; subgenera: Wilks' lambda $=0.00, F_{(3,15)}=311.6, P<0.0001$; species: Wilks' lambda $=0.00, F_{(3,63)}=113.05$, $P<0.0001)$. The statistically significant separation within taxonomic units occurred along all tree axes (ANOVAs for groups: $F_{(3,250)}=69.37,555.46$, and 32.94, respectively, $P<0.0001$; ANOVAs 
313 for subgenera: $F_{(5,248)}=262.58,479.63$, and 122.72, $P<0.0001$; ANOVAs for species: $F_{(21,232)}=$ $314150.51,164.95$, and 51.62, $P<0.0001)$.

315 The differentiation of the particular quantitative characters of the endocarps between 316 individual groups, subgenera, and species as shown in Figs. 3-5. The endocarp length (SL) and 317 thickness (ST) were the best diagnostic characters as they significantly differentiated each group 318 from the others (Figs. 3A and 3D; post-hoc tests, $p<0.05$ ). The length and thickness of the 319 endocarps (SL and ST) were the greatest in the CC group and the smallest in the DW group. The 320 endocarp width (SW) and length-to-width ratio (SL/SW) also assumed the highest values in the 321 CC group and the smallest values in the DW group. However, these two characters did not differ 322 significantly between the BW and BB groups (Figs. 3G and 4A). The highest number of vascular 323 bundles $(\mathrm{VN})$ was present on endocarps of species from the BW group. This character 324 distinguished all groups, with the exception of BB and DW (Fig. 4D).

325

Considering the differentiation in quantitative characters within particular subgenera, the 326 endocarp length (SL) also revealed a significant difference between subg. Mesomora and subg. 327 Kraniopsis as well as between subg. Cynoxylon and subg. Syncarpea (Fig. 3B). Subgenera 328 Mesomora and Kraniopsis also differed significantly according to endocarp thickness (ST) and 329 width (SW) (Figs. 3E and 3H). The endocarp length/width ratio (SL/SW) significantly differed between subg. Cynoxylon and subg. Syncarpea (Fig. 4B). The number of vascular bundles (VN) 331 did not differ between subgenera Mesomora and Kraniopsis, between Cornus and Cynoxylon, and 332 between Cynoxylon, Syncarpea, and Arctocrania (Fig. 4E).

Most of the species clustered in the same groups and subgenera exhibited great similarities 334 in the analysed quantitative characters, but with some exceptions. The endocarp length (SL) and 335 $\mathrm{SL} / \mathrm{SW}$ ratio of C. kousa (Syncarpea) were significantly lower compared to those of C. florida and C. nuttallii (Cynoxylon) (Figs. 3C and 4C; species nos. 18-20). The endocarp thickness (ST) of $C$. 337 alba, C. bretschneideri, C. occidentalis, and C. sericea were significantly smaller than those of 338 other BW species (Fig. 3F; species nos. 1, 5, 11, and 14). The endocarp width (SW) of $C$. canadensis was significantly smaller than that of C. suecica (Fig. 3I, species nos. 21-22). Some similarities between species clustered in different subgenera were also observed. C. kousa (Synacrpea) and both C. canadensis and C. suecica from subg. Arctocrania did not differ (chisquare test, $p>0.05$ ) in endocarp length (SL) and SL/SW ratio (Figs. 3B, 3C, 4B, and 4C). In turn, 
343 the endocarp thickness (ST) of Cornus officinalis (chi-square test, $p>0.05$ ) did not differ from 344 those of species from subg. Cynoxylon and Syncarpea (Figs. 3E and 3F).

345 An apical cavity was observed in stones of 12 out of 22 species under study. However, for 346 most of these species, it occurred sporadically (C. australis, C. bretschneideri, C. drummondii, C. 347 foemina, C. macrophylla, C. obliqua, C. sanguinea, C. walteri, and C. officinalis). Thus, the apical 348 cavity length and width (ACL, ACW) were analysed in detail only for C. alternifolia, C. 349 controversa (Mesomora), and C. mas. Both species of subg. Mesomora differed from each other 350 in ACL and ACW. Furthermore, their cavities were significantly longer and wider comparing to 351 C. mas (Figs. 5A and 5B).

\section{Qualitative characters}

353

354 355
The results of the chi-square test of independence showed significant differences between examined dogwood groups, subgenera, and species in all the qualitative morphological characters of the endocarps (Table 6).

None of the examined characters were uniform within all groups, subgenera, or species. However, it was possible to distinguish uniform characters for particular groups, subgenera, and species (Table 7).

The qualitative characters were the least differentiated in the DW group, where four characters of endocarps were uniform: smooth surface (SSF), absence of apical cavity (ACP), flat vascular bundles (VBP), and unforked vascular bundles (FV). Additionally, two typical characters ( $>90 \%$ of the occurrences) were identified in DW: rounded base $(\mathrm{BSH})$ and absence of distinctive furrow (DF), with $92.2 \%$ and $96.8 \%$ percentage of occurrence, respectively. In the CC group, four characters were considered uniform: spherical = globose endocarps $(\mathrm{SSH})$, rounded or truncated apex (ASH), smooth endocarp surface (SSF) and absence of distinctive furrow (DF). In the BB group, two uniform characters were observed: absence of the apical cavity (ACP) and unforked vascular bundles $(\mathrm{FV})$, while rounded or truncate apex (ASH) was recognised as a typical character, with a percentage of occurrence of $91.1 \%$. The endocarps of BW species were the most heterogeneous, and neither uniform nor typical characters in this group were present.

Four characters were found to be uniform in the following subgenera: Mesomora [rounded or truncate apex (ASH), presence of apical cavity (ACP), sunken vascular bundles (VBP) and forked vascular bundles $(\mathrm{FV})$ ]; Cornus [spherical=globose endocarps $(\mathrm{SSH})$, rounded or truncate apex (ASH), smooth endocarp surface (SSF), absence of distinctive furrow (DF)]; Cynoxylon 
374 spherical=globose endocarps $(\mathrm{SSH})$, rounded or truncate apex $(\mathrm{ASH})$, smooth endocarp surface 375 (SSF), absence of distinctive furrow (DF)]; Arctocrania [smooth endocarp surface (SSF), absence 376 of apical cavity (ACP), flat vascular bundles (VBP), unforked vascular bundles (FV)]. In subg. 377 Syncarpea three uniform characters were found: irregular shape (SSH), absence of apical cavity 378 (ACP) and sunken vascular bundles (VBP) while in subg. Kraniopsis no uniform characters were 379 present.

With reference to uniform characters recognised in particular species, the smooth endocarp

381

382

383

384

385

386

387

388

389

390

391

392

393

394

395

396

397

398

399

400

401

402

403 surface (SSF) was observed in endocarps of 16 species (Figs. 6-7). In turn, flat vascular bundles (VBP) were present in endocarps of 12 species, the absence of distinctive furrow (DF) was uniform for 7 species, a spherical=globose endocarp $(\mathrm{SSH})$ was uniform for 6 species, a rounded or truncate apex (ASH) was uniform for 5 species, unforked vascular bundles (FV) were uniform for 4 species, sunken vascular bundles (VBP) and a rounded basal shape for the endocarp (BSH) were uniform in three species, and raised vascular bundles (VBP) were uniform for 2 species (Figs. 6-7, Table 7, Supplemental File 5).

Considering the obtained results based on the analyses of the uniform characters, no differences were found between the CC and DW groups in terms of smooth endocarp surface (SSF) and between the BB and DW groups in terms of unforked vascular bundles (FV). With reference to subgenera, no differences were found between Cornus and Cynoxylon in terms of spherical endocarps (SSH); between Mesomora and Cornus in terms of rounded or truncate apex (ASH); between Cornus, Cynoxylon, and Arctocrania in terms of smooth endocarp surface (SSF); between Mesomora and Syncarpea in terms of sunken vascular bundles (VBP); and between Cynoxylon, Syncarpea, and Arctocrania in terms of unforked vacular bundles (FV). The results concerning the occurrence of uniform characters in individual species are presented in Table 7.

The analysis results based on the examination of all endocarp characters concerning the differentiation between the studied groups, the subgenera and species showed that the endocarp shape (SSH), the apical shape (ASH), the position of vascular bundles on the endocarp surface (VBP), and the absence/presence of distinctive furrow (DF) enabled the differentiation of each group from the others (chi-square tests, $p<0.05$ ) (Figs. 6A, 6D, 7D, and 7J). The basal shape of the endocarp (BSH), the absence/presence of apical cavity (ACP), and the absence/presence of forked vascular bundles (FV) separated the examined groups from each other, with the exception 
404 of BB and DW (Figs. 6G, 7A, and 7G). The endocarp surface (SSF) enabled the differentiation of 405 all the groups except the CC and DW (Fig. 6J).

$406 \quad$ None of the characters under study differentiated between all subgenera. However, the 407 rounded or truncate apex (ASH) significantly distinguished between subg. Cornus and subg. 408 Cynoxylon and Syncarpea, while subg. Cornus and Mesomora did not differ according to ASH 409 (Fig. 6E). The rounded basal shape (BSH) was present in $68.7 \%-92.2 \%$ of endocarps of subg. 410 Kraniopsis, Mesomora, Cornus, Syncarpea, and Arctocrania. Subgenus Cornus did not differ 411 between subg. Kraniopsis and Mesomora in terms of BSH, while the differentiation between subg. 412 Syncarpea and Arctocrania was significant despite the observed similarity (Fig. 6H). The smooth 413 endocarp surface (SSF) was predominant among subgenera Kraniopsis, Mesomora, Cornus, 414 Cynoxylon, and Arctorania (78.3\%-100\% of the occurrences within these subgenera), with the 415 only exception of subg. Syncarpea; no differences were found between subg. Kraniopsis416 Mesomora and Cornus-Cynoxylon-Arctorania. In subg. Syncarpea (C. kousa), 86.3\% of endocarps 417 had rough surfaces; thus, this subgenus differed significantly from all others in terms of SSF (Fig. $4186 \mathrm{~K}$ ). The rough endocarp surface (SSF) was recognised also in $95.1 \%$ and $100 \%$ of endocarps of 419 two Kraniopsis species: C. amomum and C. obliqua, respectively (Fig. 6L). The sunken vascular 420 bundles (VBP) did not differ between subg. Mesomora and Syncarpea, while significant 421 differences in VBP were found between all other subgenera (Fig. 7E). With reference to the 422 presence of unforked vascular bundles (FV), there were no differences between subg. Cynoxylon, 423 Syncarpea, and Arctocrania (Fig. 7H). The significant differentiation in FV was found within the 424 subg. Cornus as unforked vascular bundles were present on 100\% of Cornus mas and on 42.2\% 425 of $C$. officinalis endocarps. In turn, the unforked vascular bundles were present on $99.5 \%$ of $C$. 426 kousa endocarps (Syncarpea) (Fig. 7I, Supplemental File 5). On endocarps of Kraniopsis and 427 Mesomora, the forked vascular bundles were present in $77.7 \%$ and $99.8 \%$, respectively (Fig. $7 \mathrm{H})$. 428 The absence of distinctive furrow (DF) was predominant on endocarps of subg. Mesomora (96.6\%) 429 and Arctocrania (96.8\%), and no differences were found between these two subgenera. Same as 430 above, the following pairs of subgenera: Mesomora-Cornus (96.6\%-100\%) and Cornus431 Arctocrania (100\%-96.8\%) were very similar in terms of the absence of DF. However, they still 432 had differences. The presence of DF was predominant among the endocarps of the Cynoxylon and 433 Syncarpea specimens (90.7\% and 86.3.\%), and no differences between these two subgenera were 434 found (Fig. 7K). 
435

436

437

438

439

440

441

442

443

444

445

446

447

448

449

450

451

452

453

454

455

456

457

458

459

460

461

462

463

464

\section{Qualitative and quantitative characters}

Similarity coefficients calculated for the morphological characters of the endocarps showed a high similarity between the CC, BB, and DW groups (Table 8). In all comparisons, the BW group had the lowest similarity to other groups. In terms of quantitative characters, the BB-DW groups were clearly the most similar (similarity coefficient $S=0.71$ ). In the case of qualitative characters, the CC-DW groups were the most similar $(S=0.45)$, but the groups CC-BB were only slightly less similar $(S=0.42)$. Considering both quantitative and qualitative characters, the BB-DW groups were again most similar $(S=0.54)$.

\section{Endocarp cross-section}

The discriminant analysis showed that the characters of internal structure of endocarps clearly distinguished the species of the CC group from other dogwoods and that the BW group overlapped with the DW and BB groups (Fig. 8). All the examined characters had significant discriminatory power (Table 9). There was a strong positive correlation between the valve thickness (GVT) and the first discriminant function. Similarly, a positive but weaker correlation was found for the next two characters: the septum width (SMW) and the thickness of the endocarp wall divided by the diameter of the endocarp, multiplied by100 (WTP). The first discriminant function distinguished C. mas from other species and the DW group from the BB group. The second discriminant function separated $C$. officinalis. The WTP ratio was strongly and negatively correlated with this function. The other two characters (GVT and SMW) were less strongly correlated. (Table 9).

The Kruskal-Wallis tests $(H)$ confirmed that GVT, SMW, and WTP were significantly different within each analysed level: group, subgenus, and species (Table 10). The valve thickness (GVT) and the WTP ratio significantly differentiated the stones of specimens from all four group (Figs. 9A and 9G). The highest values of both characters were noted in the CC, whereas the lowest were in the DW. The third character, that is, the septum width (SMW), enabled only the distinction between the BW and BB from DW (Fig. 9D).

The subgenera from the BW group differed significantly according to the examined crosssection characters. When comparing the endocarps of Mesomora and Kraniopsis (Figs. 9B, 9E, and 9H), the valve thickness (GVT) and the septum width (SMW) were significantly higher in the former, while the WTP ratio was significantly higher in the latter. In the BB group, the Cynoxylon 
465 species had stones with higher values of septum width (SMW) than Syncarpea representatives 466 (Fig. 9E).

467 Among the particular species, the examined characters differentiated clearly between $C$. 468 mas and $C$. officinalis in terms of the presence and absence of the septum (it was absent in $C$. 469 officinalis) and the WTP ratio, which was significantly higher in C. officinalis (Figs. 9F and 9I, 470 species nos. 16 and 17). The above-mentioned character differed between $C$. canadensis and $C$. 471 suecica (Fig. 9I, species nos. 21 and 22).

472 Secretory cavities occurred only on the endocarp wall of C. mas and C. officinalis fruit 473 stones. The average number of cavities (DCN) was significantly higher in $C$. mas endocarps 474 (Mann-Whitney $U$ test: $U=9.5 ; Z=4.15 ; p=0.000$; Fig. 10).

\section{SEM analysis}

476 The endocarps of most of the examined dogwoods were composed of the isodiametric 477 sclereids with evenly thickened and lignified cell walls with numerous pits. In the structure of the 478 endocarps of C. walteri from the BW group and those of C. florida, C. nuttallii, and C. kousa from 479 the BB group, the elongated sclereids were also observed (Table 11, Figs. 11G, 12I, 12K, and 480 12M).

In the endocarps of the species from the CC group (C. mas and C. officinalis), the outer 482 (OE) and inner endocarps (IE) were distinguished. The OE was composed mostly of isodiametric 483 sclereids and elongated fibrous cells surrounding the secretory cavities. The IE, interpreted also as the internal epidermis system (sensu Kaniewski \& Hausbrandt 1968), was composed of approximately six layers of parallel fibres with evenly thickened cell walls and numerous pits; it was surrounding the seed chambers (Figs. 12A and 12C).

It was difficult to distinguish the inner endocarp (IE) in most of the other species from the BB, BW, and DW groups. However, in endocarps of two species, C. walteri and C. sericea, the 489 groups of cells with slightly thinner cell walls, compared to the whole endocarp, were observed to surround the seed chambers (Figs. $11 \mathrm{G}$ and 13D). Additionally, in the OE of four BW species (C. alternifolia, C. sericea, C. drummondii, and C. australis), the crystals were observed (Table 11, 492 Figs. 11M , 13E, 13K, and 13U).

Immediately under the surface of the endocarp, the transitional sclereid zone (TS) was present in most of the species. It was composed of 5(3)-1 layers of thin-walled cells (compared 495 with the rest of the endocarp). These cells were slightly elongated and flattened in the plane parallel 
496 to the stone surface (Table 11, Figs. 11A, 11C, 11I, 11M, 12D, 12I, 13A, 13D, 13E, 13G, 13J, 497 13M, and 13P).

$498 \quad$ Isodiametric and elongated sclereids with differently thickened cell walls also appeared in 499 the septa, which was present in the stones of all examined dogwoods, except $C$. officinalis. The 500 differences in the structure of septa, depending on the degree of the cell wall thickness, were 501 observed on the cross-sections and longitudinal sections of the stones. Three types of the septa 502 were distinguished according to the cell wall thickness: (1) solid septa built in the cells with 503 strongly thickened cell walls (Figs. 11B, 11D, 11P, 12B, 12L, and13L), (2) partly openwork septa 504 built in the outer part of the cells with strongly thickened cell walls and in the middle of the cells 505 with thinner cell walls (Figs. 11F, 11H, 11N, 12F, 12H, 12N, 13B, 13F, 13N, 13Q, and 13T), and 506 (3) openwork septa entirely composed of cells with slightly thickened walls and with large cell 507 lumina (Figs. 11J, 11L, 12J and13H). In most of the species from the BW, BB, and DW groups, 508 crystals were observed in the septa (Table 11; Figs. 11B, 11D, 11F, 11H, 11J, 11P, 12H, 12J, 12L, $50912 \mathrm{~N}, 13 \mathrm{C}, 13 \mathrm{I}, 13 \mathrm{O}, 13 \mathrm{R}$, and 13U). A little different septa structure was observed in C. mas, a 510 representative of the $\mathrm{CC}$ group. The septa were built from narrow strongly elongated fibres. 511 Additionally, small secretory cavities were present in the septa (Fig. 12B).

512 The endocarp surface micro-ornamentation pattern was reticulate for most of the species 513 under study. Surface cells were similar in size for particular species, mostly quadrangular to 514 polygonal, sometimes rounded or irregular in their outline (Figs. 14-16). For some species like $C$. 515 sericea, C. sanguinea, or C. amomum, the cellular pattern was less distinct (Figs. 14D, 14N, and 516 15J). The biggest cells were observed on C. mas, C. officinalis, and C. canadensis endocarps ( Figs. $51716 \mathrm{~B}, 16 \mathrm{D}$, and 16H). The anticlinal cell walls were straight and raised for most of the species but 518 were wavy on $C$. racemosa and $C$. controversa endocarps, the two species from different 519 subgenera: Kraniopsis and Mesomora, respectively (Figs. 15B and 15P). In C. alba, C. 520 occidentalis, C. drummondii, C. bretschneideri, C. racemosa, and C. foemina, the specific 521 constrictions and spherical thickenings were present on the anticlinal cell walls (Figs. 14B, 14F, $52214 \mathrm{~J}, 14 \mathrm{~L}, 15 \mathrm{~B}$, and 15F). The outer periclinal cell walls were flat or concave, most often without 523 the secondary sculpture (Table 12$)$. The exceptions were the endocarps with the verrucose $(C$. 524 sericea, C. occidentalis, and C. drummondii), striate (C. sanguinea and C. amomum), punctate ( $C$. 525 australis), or foveate (C. kousa) secondary micro-ornamentation pattern (Figs. 14D, 14H, 14J, $52614 \mathrm{~N}, 14 \mathrm{P}, 15 \mathrm{~J}$, and 16N). 


\section{Discussion}

528 The present research provides documentation of the great diversity of the endocarp 529 characters and indicates the usefulness of some of them in the identification and systematic 530 assessment of many Cornus species. The results are related to recent studies on taxonomy (Schulz, 531 2011, 2012; Zieliński et al., 2014; Woźnicka et al., 2015), and they refer to published phylogenies 532 of the genus Cornus (Murrell, 1993; Xiang et al., 2006).

\section{Endocarp morphology}

\section{Quantitative characters}

Considering the taxonomic importance of the examined quantitative characters, the endocarp length (SL) and its thickness (ST) were identified as the best diagnostic characters, as

537

538

539

540

541

542

543

544

545

546

547

548

549

550

551

552

553

554

555

556

557 they significantly differentiated each group from others. The number of vascular bundles (VN) was the character that significantly differentiated almost all BW species from the red-fruited species (CC, BB, and DW). It was shown that the specimens representing the KraniopsisMesomora complex (BW) had significantly more vascular bundles than the specimens representing the subgenera Cornus, Cynoxylon, Syncarpea, and Arctocrania (CC) (Figs. 4E and 4F). Within the red-fruited dogwoods, the average number of vascular bundles (VN) differed significantly for the CC, BB, and DW species, with the exception of C. nuttallii (Cynoxylon, BB) (Figs. 4D, 4E, and 4F). Such results agree with phylogenies based on molecular evidence (Xiang et al., 2006). However, the similarity of C. mas and C. officinalis (subg. Cornus, CC) with $C$. nuttallii in terms of VN supports Murrell's (1993) morphological phylogeny.

The results on the subgeneric level showed that there were no differences in the endocarp length (SL) between Syncarpea and Arctocrania species. Additionally, the same character significantly differentiated between subg. Cornus and subgenera Cynoxylon and Syncarpea as well Arctocrania (Fig. 3B). Exactly the same similarities/differences were found according to the SL/SW ratio (Fig. 4B). The differentiation of SL and SL/SW found among the above-mentioned subgenera indicates that the described results support the molecular (Xiang et al., 2006) rather than the morphological (Murrell, 1993) phylogenies.

Considering other studied quantitative characters, such as the endocarp width (SW) and its thickness (ST), the results were not so clear. The SW analyses showed that subgenera Cornus and Mesomora did not differ in that character, which may highlight the results of the parsimony analysis of matK, according to which CC-BW was the pair of sister clades (Xiang et al., 2006). In 
558 turn, the stone thickness (ST) did not differ significantly between subg. Cornus and subg.

559 Cynoxylon and Syncarpea, which supports Murrell's (1993) phylogeny.

560 Qualitative characters

561 Among the qualitative characters, the endocarp shape in vertical projection (SSH), apical 562 shape (ASH), basal shape (BSH), smooth/rough endocarp surface (SSF), position of vascular 563 bundles on endocarp surface (VBP), absence/presence of forked vascular bundles (FV), and 564 absence/presence of distinct furrow (DF) were taxonomically important characters, as they 565 allowed us to differentiate between particular species, subgenera, or groups.

566

The differentiation in the stone shape ( $\mathrm{SSH}$ ) allowed the selection of the species with

567 spherical, intermediate, flattened, and irregular stones. Flattened fruit stones were quite often

568

569

570

571

572

573

574

575

576

577

578

579

580

581

582

583

584

585

586

587

present for species from BW (33.7\%) and DW (42.9\%) groups, while spherical endocarps were uniform for the CC group. Irregular stones were uniform for Syncarpea and allowed a clear distinction of $C$. kousa from the rest of the examined dogwoods. The stone shape (SSH) together with the degree of flattening of the stone, i.e. its thickness (ST) and length-to-width ratio (SL/SW) were often used in the past to analyse the diversity of the endocarps of very similar and phylogenetically closely related species (e.g., C. alba, C. sericea, and C. occidentalis from the BW group) (Fosberg, 1942; Szafer \& Pawłowski, 1959; Rehder, 1967; Bean, 1976; Seneta, 1994; Rutkowski, 2004; Xiang et al., 2006; Schulz, 2012; Zieliński et al., 2014; Woźnicka et al., 2015). However, the results of recent studies concerning dogwoods' morphology (Schulz, 2012; Zieliński et al., 2014; Woźnicka et al., 2015) and our analyses of ST and SL/SW average values have shown that the ranges of these characters mostly overlap; thus, they do not explain sufficiently the species status of these closely related taxa. Additionally, the results concerning the flattened shape (SSH) of C. alba, C. sericea, and C. occidentalis endocarps (97.8\%, 92.1\%, and 94.4\%, respectively) and the presence of distinctive furrow running longitudinally on the lateral faces of their endocarps (DF) $(53.8 \%, 77.2 \%$, and $87.9 \%$, respectively) also indicated a close similarity between C. alba, C. sericea, and C. occidentalis (BW). Considering these three species, Schulz (2012) proposed the new taxonomic approach of $C$. alba s.l. with subsp. alba and subsp. stolonifera. He treated $C$. occidentalis at the rank of variety below subspecies stolonifera of $C$. alba. This new taxonomic approach was accepted by Zieliński et al. (2014) and Woźnicka et al. (2015) and supported by our results.

Peer] reviewing PDF | (2020:11:55179:2:0:NEW 10 Aug 2021) 
588

589

590

591

592

593

594

595

596

597

598

599

600

601

602

603

604

605

606

607

608

609

610

611

612

613

614

615

616

617

618

The lack of significant differentiation in the endocarp apical shape (ASH) and its basal shape (BSH) supports close relationships between particular species from the subg. Kraniopsis (BW) (e.g., North American species C. amomum, C. obliqua, C. foemina, and C. racemosa or European species C. sanguinea and C. australis). With reference to C. amomum and C. obliqua, some other morphological similarities between these two species [e.g., the rough endocarp surface (SSF) (95.1\% and 100\%, respectively) and the uniform raised vascular bundles (VBP)] were also found. Referring to $C$. sanguinea and C. australis, the flat vascular bundles (VBP) with $93.7 \%$ and $100 \%$ of the occurrences and unforked vascular bundles (FV) with over $91.5 \%$ of the occurrences indicated their close similarity. All the described results support Schulz (2012), who suggested that $C$. obliqua and $C$. australis should be classified as subspecies within $C$. amomum and $C$. sanguinea, respectively. The results also complement the earlier findings describing the morphological and molecular similarities of these species (Wilson, 1964; Bean, 1976; Ball, 2005; Xiang et al., 2006; Schulz, 2012; Woźnicka et al., 2015).

The noticeable variation in the form of endocarp apical shape (ASH) allowed the distinction between examined Arctocrania species (DW). In turn, the rounded or truncated apex was recognised as a uniform character for C. mas and C. officinalis (CC). According to Bojnanský \& Fargašová (2007), C. mas stones have a pointed apex, whereas C. officinalis stones have a blunt apex. It is most likely that the differences between the results of our study and the cited data were caused by the inverse description of the stone apex and the stone base by Bojnanský \& Fargašová (2007). The rounded or truncated apex (ASH) was also recognised as a uniform character for alternate-leaf dogwoods C. alternifolia and C. controversa (subg. Mesomora). However, it should be noted that this character was somewhat combined with the presence of distinct ACP, which was present on the endocarps of these two species and was recognised as a taxonomically important character. It allowed for a significant separation of two alternate-leaf dogwoods C. alternifolia and C. controversa (subgen. Mesomora, BW) from species belonging to subg. Kraniopsis, which was in line with earlier results by other authors (Eyde, 1988; Xiang \& Boufford, 2005; Schulz, 2011, 2012; Woźnicka et al., 2015). Our results confirmed also the presence of noticeable, but clearly much smaller, apical cavities on the stones of several Kraniopsis species, which was described earlier by Woźnicka et al. (2015). Apart from the BW group, much smaller apical cavities were present on the endocarps of examined species from subg. Cornus. They were frequent on C. mas $(99.9 \%)$ fruit stones and occurred sporadically on C. officinalis (16.1\%) endocarps. We also 
619 observed a shallow depression on C. volkensii stones (unpublished data). Eyde (1988) did not 620 clearly state whether cavities could be found in these species nor in what form. As far as the species 621 from the group of large-fruited edible dogwoods (CC) were concerned, the author only described 622 the apical cavity that was wide and shallow in C. volkensii; in C. chinensis, it had the form of a V623 shaped incision and was absent on C. sessilis endocarps. According to Manchester et al. (2010), 624 the endocarps of species belonging to subg. Cornus differ in the expression of an apical cavity. 625 These authors described a V-shaped apical notch in C. chinensis and a broad shallow cavity in $C$. 626 volkensii. The other species were described as apically rounded without or with inconspicuous 627 apical cavity. Atkinson et al. (2016) confirmed the presence of the apical cavity on stones of $C$. 628 mas, C. officinalis, and C. volkensii, together with a few other living (C. chinensis, C. eydeana, 629 and $C$. sessilis) and extinct species (C. piggae, C. ettingshausenii, and C. multilocularis). 630 According to the results, the ACP in C. mas fruit stones was significantly smaller than in endocarps 631 of C. alternifolia and C. controversa (Fig. 5). Based on the described results, the presence or 632 absence of apical cavities is a taxonomically important character. However, according to already 633 published data, it is a plesiomorphic character and thus have no value in the analysis of the 634 phylogeny of the genus (Murrell, 1996).

635 The extensive and detailed study of Eyde (1988) also includes an analysis of the variation 636 in a stone's surface. The author emphasised that the stones of the herbaceous species (DW) were 637 easy to distinguish because they were smoother than the stones in the BW group. Similar results 638 were obtained earlier by Woźnicka et al. (2015), which were confirmed in the present study. The 639 smooth endocarp surface (SSF) was found in all three groups of the red-fruited dogwoods (CC, $640 \mathrm{BB}$, and DW), but with the exception of C. kousa (Syncarpea, BB) (Fig. 6L), which agrees with 641 Eyde (1988, Figs. 13h and 13i, p. 276) who showed that C. kousa stones were irregular and rough. 642 A uniform character of smooth endocarps present in three subgenera from different groups643 Cornus (CC), Cynoxylon (BB), and Arctocrania (DW)—supports published phylogenies based on 644 morphological and molecular data (Murrell, 1993; Xiang et al., 2006).

645 The vascular bundle position on the endocarp surface (VBP) differentiated significantly 646 Kraniopsis and Mesomora species. The sunken vascular bundles were recognised as a uniform and 647 taxonomically important character for subg. Mesomora. In endocarps of Kraniopsis species, 648 mostly flat vascular bundles were present. The present results confirmed the results of Woźnicka 649 et al. (2015). The significant differentiation in VBP within the subgenera of red-fruited dogwoods 
650 (CC, BB, and DW) also indicate systematic importance of that character. The presence of flat 651 vascular bundles, which were uniform for the endocarps of a few species belonging to different 652 morphological groups, like C. officinalis (CC), C. nuttallii (Cynoxylon, BB), C. canadensis, and 653 C. suecica (DW), supports the phylogenies based on the morphological and molecular evidence 654 (Murrell 1993, Xiang et al. 2006). In turn, the presence of the unforked vascular bundles on 655 endocarp surface (FV) showed a distinct similarity between two groups of red-fruited dogwoods 656 (BB-DW), which supports the close phylogenetic relationship of these clades shown by Xiang et

657 658 659 660 661 662

663

664

665

666

667

668

669

670

671

672 673

674

675

676

677

678

679 680 al. (2006). However, there was a close similarity between C. mas (subg. Cornus) and BB species according to the presence of the unforked vascular bundles, which supports Murrell's (1993) morphological phylogeny.

The presence of distinctive furrow running longitudinally on the lateral faces of an endocarp (DF) was a strongly variable character. It was uniform only for the DW group, so no support for the published phylogenies was found according to that character. However, some of its taxonomic usefulness should be mentioned. The DF was present on 35.6\% of Kraniopsis endocarps and only on $0.4 \%$ of Mesomora fruit stones (BW). Such results agree with the results of Fosberg (1942), Schulz (2012), and Woźnicka et al. (2015). In reference to the red-fruited dogwoods, fruit stones with furrows on sides were predominant among the C. florida, C. nuttallii, and C. kousa endocarps (BB) $(86.3 \%-90.7 \%)$, while it was almost $(96.8 \%)$ or completely $(100.0 \%)$ absent on endocarps of CC and DW species. Such results indicate that the presence of DF on the endocarps of most of big-bracted species may be helpful in distinguishing them from other red-fruited dogwoods.

The calculated similarity coefficients allowed us to check whether the described morphological similarities between the studied groups and subgenera reflect their current phylogenetic relations. The similarity coefficients (Table 8) calculated jointly for the qualitative and quantitative characters showed that the endocarps of big-bracted dogwoods (BB) and dwarf dogwoods (DW) were the most similar. Such results indicated support for molecular phylogenies (Xiang et al., 2006). When only qualitative characters were considered, the closest similarity of groups CC-DW was found mainly due to the smooth endocarp surface (SSF). This character may possibly be considered a synapomorphy for CC and DW groups. However, that similarity does not directly reflect any of the published phylogenies (Murrell, 1993; Fan \& Xiang, 2001; Xiang et al., 2006).

Peer) reviewing PDF | (2020:11:55179:2:0:NEW 10 Aug 2021) 


\section{Endocarp cross-section}

682 The results concerning the internal structure of endocarps of C. mas, C. officinalis, and C. 683 volkensii (unpublished data) and the available literature data (Kaniewski \& Hausbrandt, 1968; 684 Eyde, 1988; Manchester et al., 2010) indicate that the numerous secretory cavities in both the stone 685 walls and the septa are uniform and may be identified as synapomorphy for subg. Cornus. 686 According to Manchester et al. (2010), this character is taxonomically important as it allows the 687 correct identification and classification of fossil endocarps of these species. Recently, Atkinson et 688 al. (2016) examined the anatomy of permineralised fruits from the Campanian of Vancouver Island 689 and showed that the presence of secretory cavities in the woody endocarps indicated that they were 690 assignable to the Cornus subg. Cornus. Manchester et al. (2010) also analysed the germination 691 valve thickness (GVT) and the thickness of germination valve divided by endocarp diameter 692 (WTP). The author found these parameters very useful in comparative analyses of endocarps of 693 living dogwoods and fossil materials representing the former taxa of the Cornus subg. Cornus 694 (CC). The same two characters were also included in our research, and the results were comparable 695 to C. mas and C. officinalis fruit stones. In C. mas endocarps, the WTP was 21 and the GVT was $6961.2 \mathrm{~mm}$. In C. officinalis endocarps, the WTP ratio was 28 and the GVT was $1.1 \mathrm{~mm}$. According 697 to Manchester et al. (2010), the analogous data were 20 and 0.8-1.2 $\mathrm{mm}$ for C. mas stones and 2269834 and $0.9 \mathrm{~mm}$ for C. officinalis endocarps.

699 The present research confirmed that the endocarp tissue of CC and BB species consists of 700 isodiametric and elongated sclereids. Takahashi et al. (2003) named them "rise grain shaped 701 sclereids." Interestingly, the elongated sclereids were also present in the endocarps of C. walteri 702 (BW), which means that this character was shared by two "unrelated" clades. To resolve whether 703 it was a possible homoplasy, cladistic analyses were needed. With reference to the CC group, it 704 was confirmed that the outer and inner regions of endocarp were clearly distinguished (Manchester 705 et al., 2010; Morozowska et al., 2013; Atkinson et al., 2016; Stockey et al., 2016; Atkinson et al., 706 2017).

707 The present study also described several new findings potentially helpful in the taxonomic 708 examination of living and fossil woody fruit stones of different Cornus species. Endocarps of 709 species belonging to subgenera Kraniopsis and Mesomora (BW) and of species from subgenera 710 Syncarpea and Cynoxylon (BB) differed significantly in terms of GVT, SMW, and WTP (Figs. 711 9B, 9E, and 9H, respectively). Among red-fruited dogwoods, the highest values of GVT and WTP 
712 were typical for endocarps of CC species (Figs. 9A and 9G), while the narrowest septum (SMW)

713 was typical for endocarps of DW species (Figs. 9D-9F), which correlated with their lowest

714 dimensions (SL, ST, and SW) (Figs. 3A-3I).

\section{SEM analyses}

716 The comparisons between the internal structure and the micromorphology of endocarps of

717 closely related species also highlighted some significant differences of taxonomic importance.

718 Cornus alternifolia and C. controversa (BW, subg. Kraniopsis and Mesomora, respectively)

719 endocarps differed according to such characters as the presence or absence of crystals in the outer

720 endocarp (OE), the number of cell layers in the transition sclereids zone (TS), the septa structure

721 (S), the cell outline, and the anticlinal walls of the surface cells (Tables 11 and 12). The presence

722 of the undulate anticlinal cell walls differed significantly between $C$. controversa and $C$.

723 alternifolia. Considering other phylogenetically, closely related species, such as C. alba-C.

724 sericea-C. occidentalis, C. amomum-C. obliqua, C. foemina-C. racemose-C. drummondii, or $C$.

725 australis-C. sanguinea (Xiang et al., 2006), the results obtained showed that some of them were

726 very similar, while the others clearly differed in terms of the internal structure and

727 micromorphology of endocarps (Tables 11 and 12). The primary sculpture of the first three species

728 was almost the same. However, $C$. sericea and $C$. occidentalis endocarps stood out with the

729 presence of the verrucose secondary sculpture. Moreover, Cornus sericea was the most different

730 species as far as endocarp's internal structure was concerned. The differences included the

731 presence of crystals in the OE, the absence of crystals in the septa, the presence of the inner

732 endocarp (IE), and the multilayered zone of transition sclereids. The presence of IE was generally

733 a rare character in BW species. Besides $C$. sericea, it was observed only in $C$. walterii stones.

734 According to Kaniewski \& Hausbrandt (1968), the inner endocarp is probably destroyed during

735 the ripening of the dogwood fruit. With reference to C. amomum and C. obliqua, no differences

736 were found in the internal structure of their endocarps, supporting the close phylogenetic

737 relationship of these species, as shown by Xiang et al. (2006). However, it should be noted that

738 the presence of the secondary sculpture on $C$. amomum endocarps was different compared to $C$.

739 obliqua, which may be of taxonomic importance. Referring to C. foemina, C. racemosa, and $C$.

740 drummondii, two of them (C. foemina and C. racemosa) were treated, together with C. macrocarpa

741 Nash (=C. asperifolia Michaux) from eastern North America, as three subspecies of $C$. foemina

742 complex due to their morphological similarity (all are white-fruited dogwoods) and many 
743 interspecific intermediate forms (Wilson, 1964). According to the results, some differences

744 between C. foemina, C. racemosa, and C. drummondii were found. They differed in the number

745 of cell layers forming the transition sclereids zone, the type of septa, and the form of anticlinal and

746 periclinal cell walls (Tables 11 and 12). It should be stressed that the undulate anticlinal cell walls

747 present on C. racemosa (subg. Kraniopsis) endocarps were exceptional among the examined

748 dogwoods. Another species with the same type of anticlinal walls was C. controversa (subg.

749 Mesomora). It turned out that this character was present on endocarps of two species with different

750 origins belonging to two different subgenera. C. racemosa is the North American species with

751 white fruits, while C. controversa is an Asian species with purplish red or bluish black fruits (Xiang

$752 \&$ Bufford, 2005). Regarding C. australis and C. sanguinea, the results showed an almost complete

753 resemblance in the internal structure and micromorphology of their endocarps. The only difference

754 concerned the presence of crystals in the $\mathrm{OE}$ of $C$. australis fruit stones (Table 11). Such findings

755 support the close phylogenetic relationship of these species described by Xiang et al. (2006).

756 Referring to red-fruited dogwoods (C. mas and C. officinalis), the cellular pattern on their

757 endocarps was characterised by the largest surface cells, and their size and the endocarp size were

758 correlated. Similarly, large surface cells were found on the endocarps of C. canadensis, but no

759 similar correlation was found. In endocarps of the red-fruited dogwoods, as in BW species, no

760 crystals were observed in OE. However, their presence was found in the stones of C. volkensii,

761 subg. Afrocrania (unpublished data). To confirm the taxonomic significance of this character, the

762 internal structure of the endocarps of all $\mathrm{CC}$ species must be examined.

763 Summing up the morphological differentiation of endocarps is largely consistent with the

764 published phylogenies within the Cornus genus. Consistency with phylogenetic relations

765 according to Xiang et al. (2006) is evident for quantitative characters and for combined quantitative

766 and qualitative characters when the BB-DW groups are the closest to each other. In the case of

767 qualitative characters, the relationships between groups are much more complex, as they show

768 almost the same similarity between CC-DW and CC-BB, showing consistency with Murrell's

769 (1993) phylogeny. However, if only the uniform characters are compared, it turns out that the CC-

770 BB groups do not have any common character, while the BB-DW groups have one common

771 character (lack of forked vascular bundles on the endocarp surface). The results clearly indicate

772 how complicated the Cornus genus is in terms of taxonomy and phylogeny.

773 Conclusions

Peer] reviewing PDF | (2020:11:55179:2:0:NEW 10 Aug 2021) 
775 structures, selected characters may be used to a greater or lesser extent in the taxonomy of the 776 genus Cornus for both living and fossil materials. Fruits are by far the most taxonomically 777 informative fossils in Cornales (Eyde, 1987, 1988; Atkinson, 2016). They are used in analyses of 778 phylogenetic relationships within Cornus and in examinations concerning the timing of the initial 779 diversification and evolution of the family Cornaceae and the basal asterid lineage, Cornales 780 (Atkinson, 2016). We have demonstrated that the morphology and internal structure of endocarps 781 allow for the differentiation of particular living species. In some cases, only one character was 782 sufficient to distinguish one taxon from others, such as irregular stones found only in C. kousa 783 (subg. Syncarpea, BB) or seven to eight vascular bundles running along the entire perimeter of the 784 stones of BW species, and might probably be considered synapomorphies for these lineages. 785 However, additional studies with the use of cladistic methods should be conducted in this case. 786 Some specimens were differentiated based on sets of characters (e.g., much longer than wider 787 endocarps with clearly visible valves and often with small apical cavities, which were 788 characteristics of the Cornus subg. The micromorphology and internal structure of endocarps were 789 also found to be potentially helpful in the taxonomy of dogwoods. The microstructure of the 790 Cornus endocarp surface has not been studied previously. Earlier studies included the 791 micromorphological structure of leaves of the selected dogwood species to assess the degree of 792 diversity of the characters under analysis and to verify their taxonomic and phylogenetic usefulness 793 (Hardin \& Murrell, 1997; Schulz, 2012; Zieliński et al., 2014; Gawrońska et al., 2019). Since one 794 of the limitations of the current study is the sample size, further replication studies on larger 795 samples of the studied Cornus subgenera and species are recommended to confirm the described 796 results.

\section{Acknowledgement}

798 We would like to thank Mrs. Ilona Wysakowska from the Department of Botany for her 799 technical assistance in preparing the manuscript.

800

801 References

802 Adams JE. 1949. Studies in the comparative anatomy of the Cornaceae. Journal of the Elisha 803 Mitchell Scientific Society 65: 218-244. 
804 Atkinson BA, Stockey RA, Rothwell GW. 2016. Cretaceous origin of dogwoods: an anatomically 805 preserved Cornus (Cornaceae) fruit from the Campanian of Vancouver Island. PeerJ 4:e2808: DOI 806 10.7717/peerj.2808.

807 Atkinson BA, Stockey RA, Rothwell GW. 2017. The early phylogenetic diversification of 808 Cornales: permineralized cornalean fruits from the Companian (Upper Cretaceous ) of Western 809 North America. International Journal of Plant Sciences 178: 556-566 DOI: 10.1086/692766.

810 Ball PW. 2005. Cornaceae. In: Tutin TG, Heywood VH, eds. Flora Europaea (Ninth printing), 811 volume: 2. Rosaceae to Umbelliferae. New York: Cambridge University Press, 313.

812 Bojnanský V, Fargašová A . 2007. Atlas of Seeds and Fruits of Central and East - European Flora. 813 Dordrecht: Springer. DOI:10.1007/978-1-4020-5362-7.

814 Eyde RH. 1987. The case for keeping Cornus in the broad Linnaean sense. Systematic Botany 12: $815 \quad 505-518$.

816 Eyde RH. 1988. Comprehending Cornus: Puzzles and Progress in the Systematics of the 817 Dogwoods. The Botanical Review 54: 233-351.

818 Fan C, Xiang Q-Y(J). 2001 . Phylogenetic relationships within Cornus (Cornaceae) based on 26S 819 rDNA sequences. American Journal of Botany 88: 1131-1138 DOI: 10.2307/2657096.

820 Fan C, Xiang Q-Y. 2003. Phylogenetic analyses of Cornales based on 26S rRNA and combined 821 26S rDNA matK-rbcL sequence data. American Journal of Botany 90: 1357-1372.

822 Fosberg FR. 1942. Cornus sericea L. (C. stolonifera Michx.). Bulletin of the Torrey Botanical 823 Club 69: 583-589 DOI: 10.2307/2481356.

824 Hardin JW, Murrell ZE. 1997. Foliar micromorphology of Cornus. The Journal of the Torrey 825 Botanical Society 124: 124-139 DOI:10.2307/2996580.

826 Howell DC. 2007. Statistical methods for psychology. Belmont, CA: Thomson Wadsworth.

827 Kaniewski K, Hausbrandt L. 1968. Badania porównawcze nad rozwojem owocni kilku gatunków 828 rodzaju Cornus. Rocznik Dendrologiczny 22: 73-90.

829 Manchester SR, Xiang X-P, Xiang Q-Y. 2010. Fruits of cornelian cherries (Cornaceae: Cornus 830 subg. Cornus ) in the Paleocene and Eocene of the Northern Hemisphere. International Journal of 831 Plant Sciences 171: 882-891 DOI:10.1086/655771.

832 Morozowska M, Gawrońska B, Woźnicka A. 2013. Morphological, anatomical and genetic 833 differentiation of Cornus mas, Cornus officinalis and their interspecific hybrid. Dendrobiology 70: 834 45-57 DOI.org/10.12657/denbio.070.005. 
835 Murrell ZE. 1993. Phylogenetic relationships in Cornus (Cornaceae). Systematic Botany 18(3): $836 \quad 469-493$.

837 Rasband WS. ImageJ. U.S. National Institutes of Health, Bethesda, Maryland, USA 838 (https://imagej.nih.gov/ij/),1997-2018.

839 Rehder A. 1967. Manual of cultivated trees and shrubs. New York: The MacMillan Co.

840 Rutkowski L. 2004. Klucz do oznaczania roślin naczyniowych. Warszawa: Wydawnictwo 841 Naukowe PWN.

842 Sárnal M, Kárný M, Benali H, Backfrieder W, Todd-Pokropek A, Bergmann H. 1999. 843 Experimental comparison of data transformation procedures for analysis of principal component. 844 Physics in Medicine \& Biology 44: 2821-2834 DOI. org/10.1088/0031-9155/44/11/310.

845 Schulz B. 2011. Die Gattung Cornus (Cornaceae), Hartriegel und Kornelkirsche, Teil 1 und 2. 846 Mitteilungen der Deutschen Dendrologischen Gesellschaft 96: 67-83.

847 Schulz B. 2012. Die Gattung Cornus (Cornaceae), Hartriegel und Kornelkirsche, Teil 3 848 Mitteilungen der Deutschen Dendrologischen Gesellschaft 97: 91-132.

849 Seneta W. 1994. Drzewa i krzewy liściaste C. Warszawa: Wydawnictwo Naukowe PWN.

850 Stockey RA, Nishida H, Atkinson BA. 2016. Anatomically preserved fossil cornalean fruits from 851 the Upper Cretaceous of Hokkaido: Eydeia hokkaidoensis gen. et sp. nov. American Journal of 852 Botany 103: 1642-1656 DOI:10.3732/ajb.1600151.

853 Szafer W, Pawłowski B. 1959. Flora Polska. Volume VIII, part V. Warszawa: PWN. Tabachnick 854 BG, Fidell LS. 2007. Using multivariate statistics. Boston: Allyn \& Bacon.

855 Thiers, B. 2021. (continuously updated). Index Herbariorum.

856 http://sweetgum.nybg.org/science/ih/ [accessed 10 November 2020].

857 Wangerin W. 1910. Cornaceae. In: Engler A, ed. Das Pflanzenreich, series IV, family 229 (Heft 858 41). Leipzig: W. Engelmann.

859 Wilson JS. 1964. Variation of three taxonomic complexes of the genus Cornus in eastern United 860 States. Transaction of the Kansas Academy of Science 67: 747-817.

861 Woźnicka A, Melosik I, Morozowska M. 2015.Quantitative and qualitative differences in 862 morphological traits of endocarps revealed between Cornus L. species. Plant Systematics and 863 Evolution 301: 291-308 DOI:10.1007/s00606-014-1073-1.

864 Xiang Q-Y, Boufford DE. 2005. Cornaceae. In: Wu ZY, Raven PH, eds. Flora of China, vol.14.

865 Beijing: Science Press and St. Louis: Missouri Botanical Garden, 206-221. 
866 Xiang Q-Y, Brunsfeld SJ, Soltis DE, Soltis PS. 1996. Phylogenetic relationships in Cornus based 867 on chloroplast DNA restriction sites: implications for biogeography and character evolution. 868 Systematic Botany 21: 515-534.

869 Xiang Q-Y, Soltis DE, Morgan DR, Soltis PS. 1993. Phylogenetic relationships of Cornus L. sensu 870 lato and putative relatives inferred from $r b c \mathrm{~L}$ sequence data. Annals of the Missouri Botanical 871 Garden 80: 723-734 DOI:10.2307/2399856.

872 Xiang Q-Y, Soltis DE, Soltis PS. 1998. Phylogenetic relationships of Cornaceae and close relatives 873 inferred from matK and rbcL sequences. American Journal of Botany 85: 285-297 874 DOI:10.2307/2446317.

875 Xiang Q-Y, Thomas DT, Zhang W, Manchester SR, Murrell Z. 2006. Species level phylogeny of 876 the genus Cornus (Cornaceae) based on molecular and morphological evidence - implications for 877 taxonomy and Tertiary intercontinental migration. Taxon 55: 9-30 DOI. org/10.2307/25065525. 878 Zieliński J, Tomaszewski D, Gawlak M, Orlova L. 2014. Kłopotliwe derenie - Cornus alba L. i 879 C. sericea L. (Cornaceae). Dwa gatunki czy jeden? Rocznik Polskiego Towarzystwa 880 Dendrologicznego 62: 9-23. 
Figure 1

Measurements of the characters of the endocarp internal structure: $C$. mas cross section (×6.9), GVT, SMW

GVT - germination valve thickness, SMW - septum width 


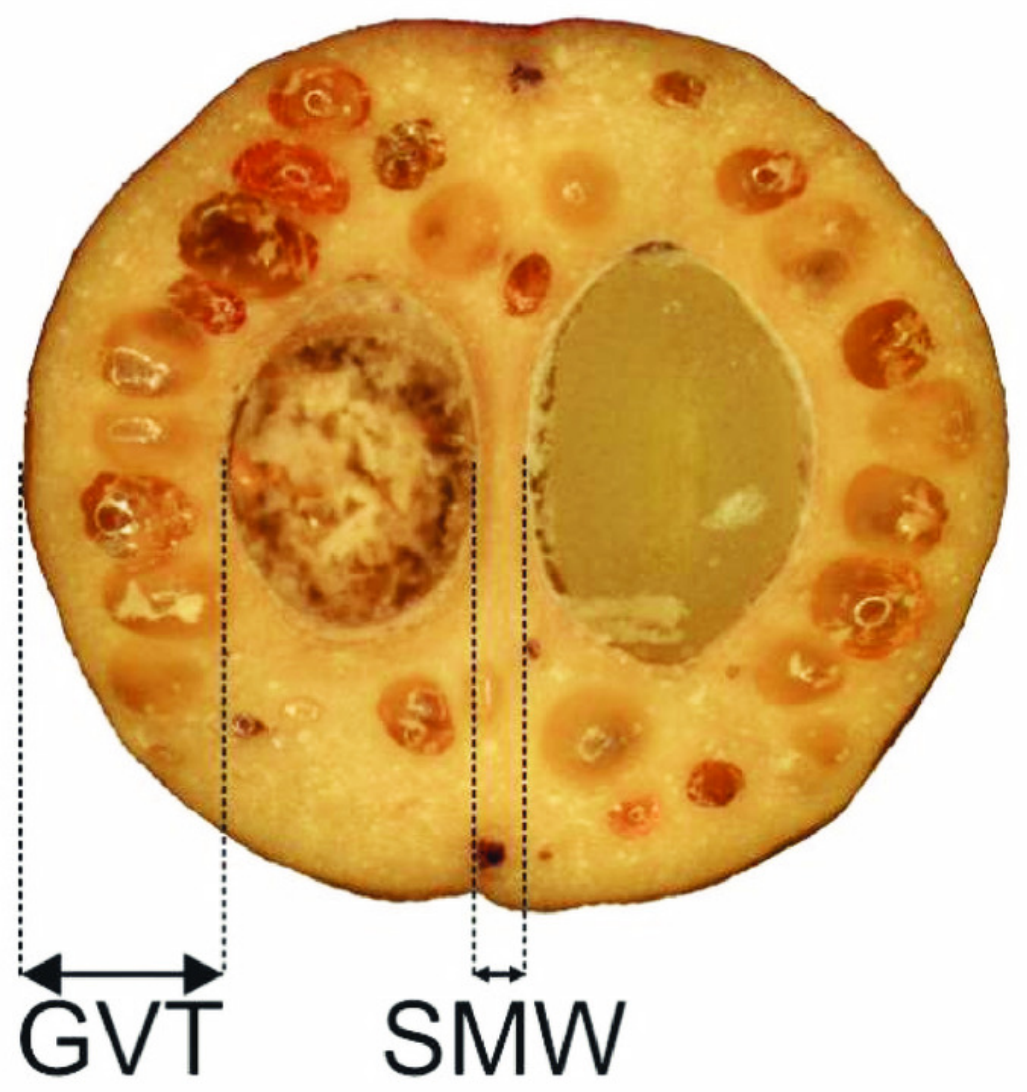


Figure 2

A scatterplot of two PCA components (V1, V2) for nine quantitative characters of the endocarps based on the mean values of 254 examined Cornus specimens

BW, CC, BB, DW - groups; Mesomora, Kraniopsis, Syncarpea, Cynoxylon - subgenera

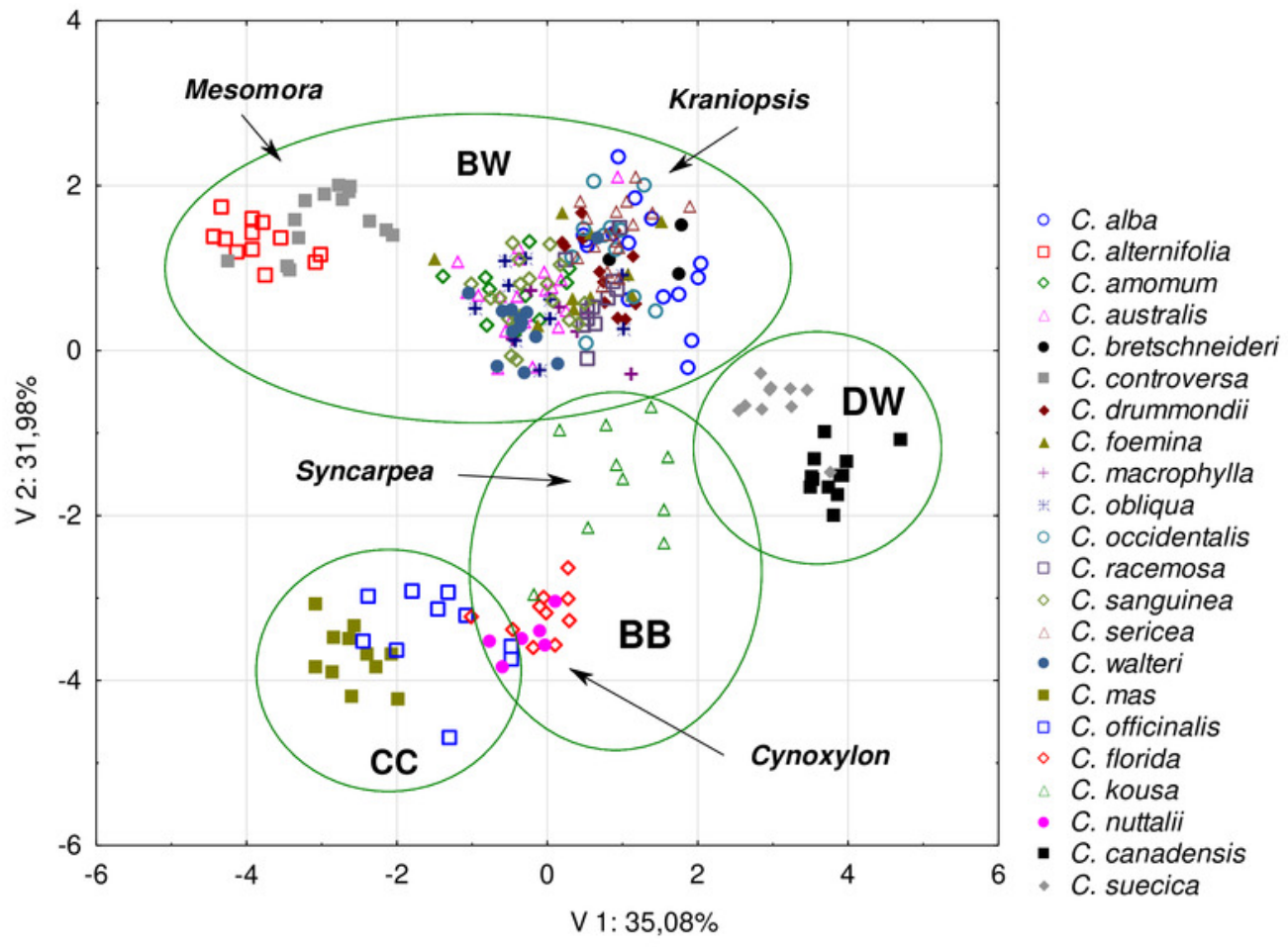


Figure 3

The mean (point), the standard deviation (box), and the minimum and maximum values (whisker) for the endocarp length (SL), width (SW), and thickness (ST)

$(A, D, G)$ groups; $(B, E, H)$ subgenera; $(C, F, I)$ species. Different lowercase letters indicate particular units differing in a given character (Dunnett's T3 tests, $p<0.05$ ). The red box marks the groups with the significant differences inside. For species description, see Table 1
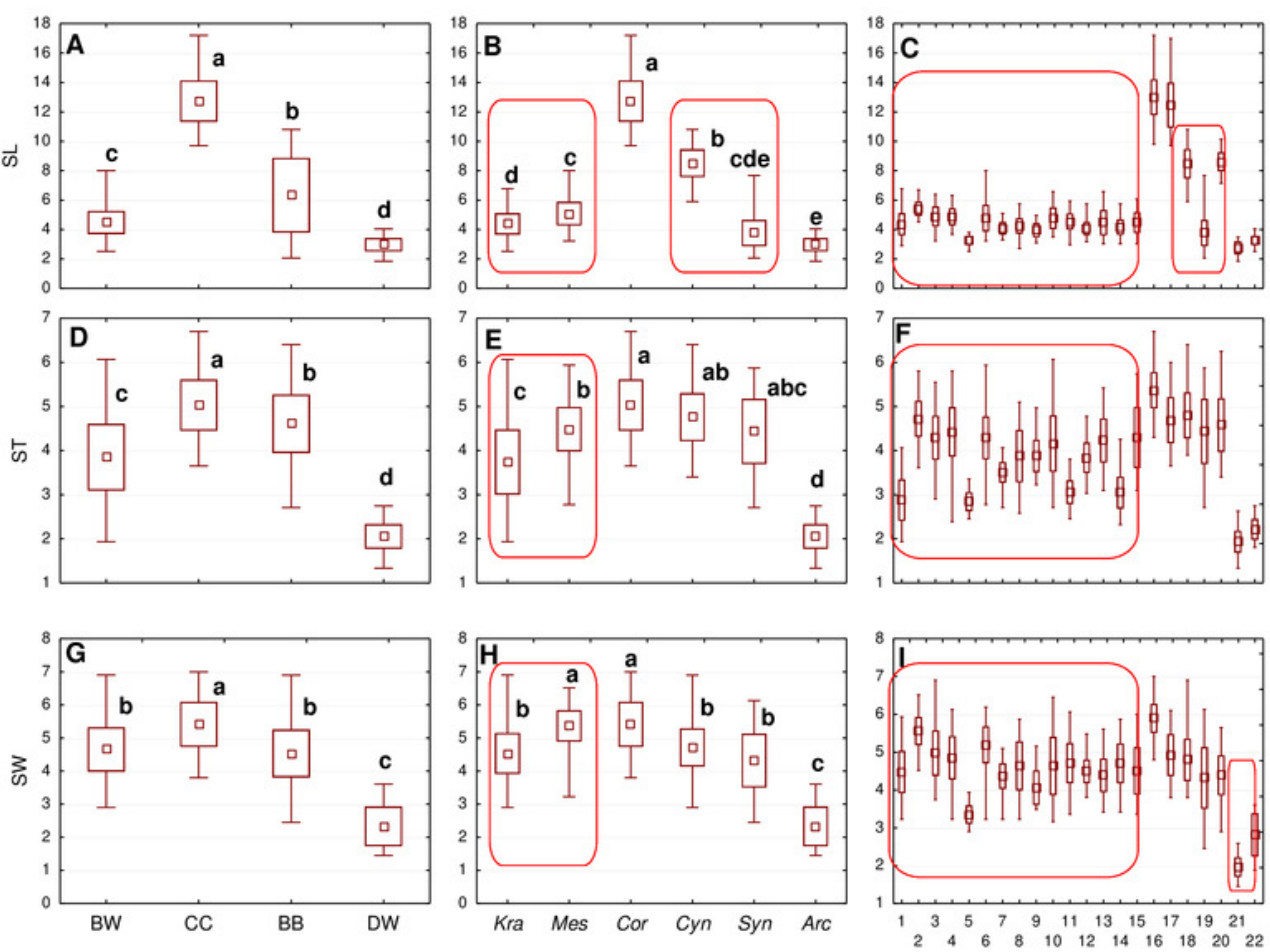
Figure 4

The mean (point), the standard deviation (box), and the minimum and maximum values (whisker) for the endocarp SL/SW ratio, and the number of vascular bundles on the endocarp surface (VN)

SL/SW - endocarp length-to-width ratio. (A, D) groups; (B, E) subgenera; (C, F) species. Different lowercase letters indicate particular units differing in a given character (Dunnett's T3 tests, $p<0.05)$. The red box marks the groups with the significant differences inside. For species description, see Table 1
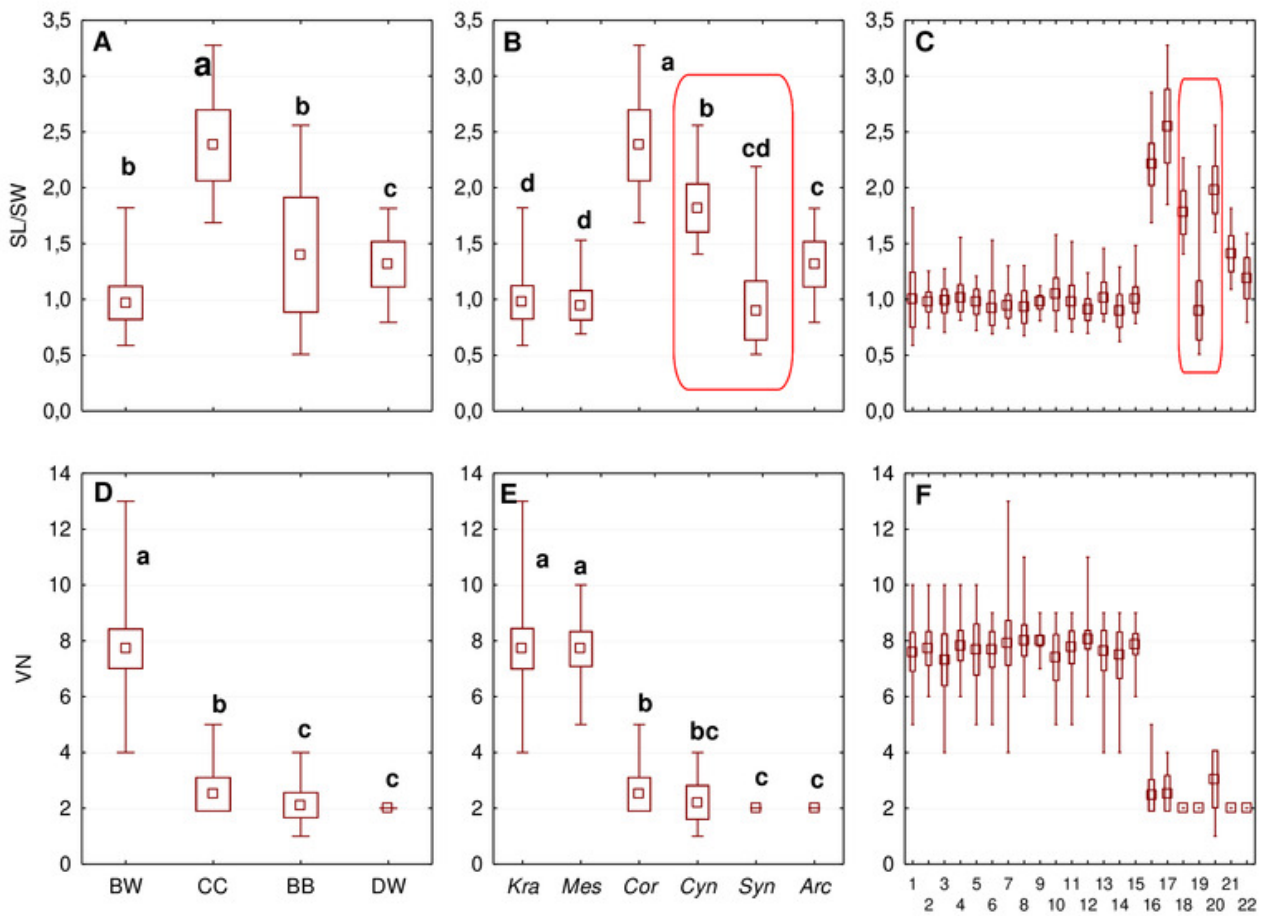
Figure 5

The mean (point), the standard deviation (box), and the minimum and maximum values (whisker) for the apical cavity length (ACL) and apical cavity width (ACW) in three Cornus species

Different lowercase letters indicate particular units differing in a given character (Dunnett's T3 tests, $p<0.05$ ). The red box marks the groups with the significant differences inside. For species description, see Table 1
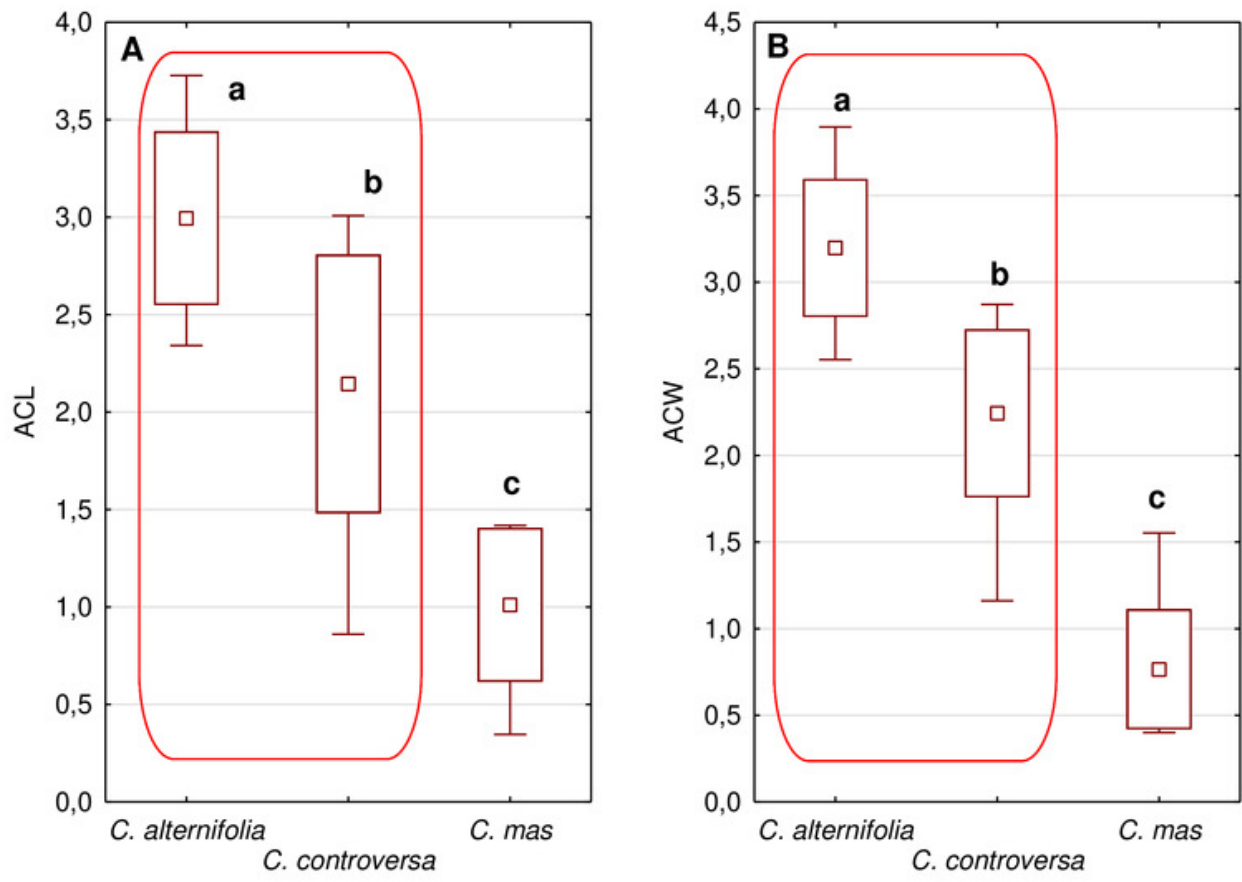


\section{Figure 6}

The endocarp shape (SSH), apical shape (ASH), basal shape (BSH), and endocarp surface sculpture (SSF)

( $A, D, G, J)$ groups; $(B, E, H, K)$ subgenera; $(C, F, I, L)$ species. Different lowercase letters indicate particular units differing in a given character (chi-square tests, $p<0.05$ ). The red box marks the groups with the significant differences inside (for species description, see Table 1). SSH: 0 - spherical = globose; 1 - intermediate; 2 - flattened $=$ compressed; 3 irregular. ASH: 0 - shortly acuminate; 1 - acuminate; 2 - wedge-shaped; 3 - rounded or truncate. BSH: 0 - shortly acuminate; 1 - long acuminate; 2 - rounded; 3 - wedge-shaped. SSF: 0 - smooth; 1 - rough 

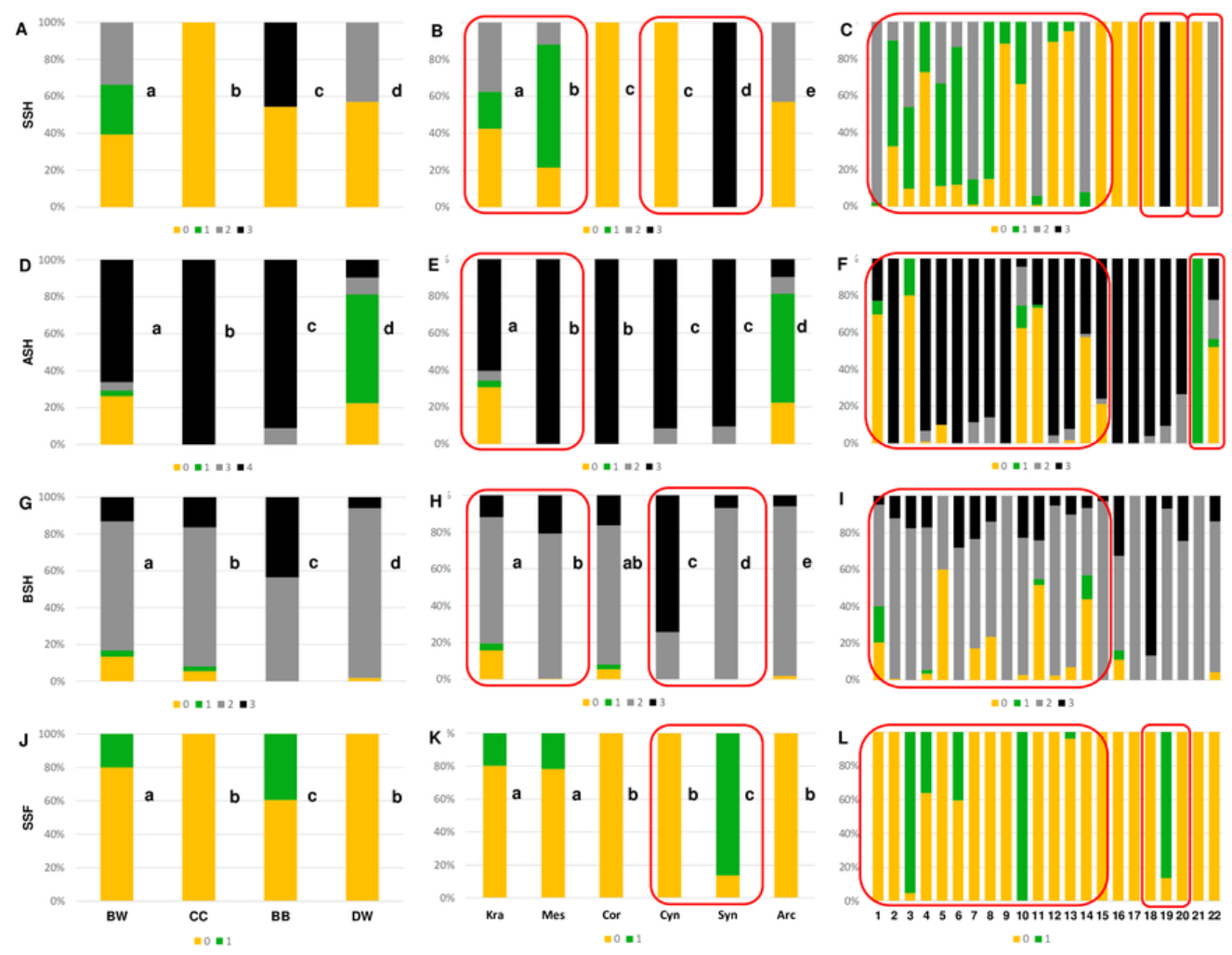


\section{Figure 7}

The presence of the apical cavity (ACP), the vascular bundle position on the endocarp surface (VBP), the presence of bifurcated vascular bundles (FV), and the presence of a distinctive furrow (DF) on Cornus endocarps

(A, D, G, J) groups; (B, E, H, K) subgenera; (C, F, I, L) species. Different lowercase letters indicate particular units differing in a given character (chi-square tests, $p<0.05$ ). The red box marks the groups with the significant differences inside (for species description, see Table 1). ACP: 0 - without cavity; 1 - with cavity. VBP: 0 - sunken; 1 - flat; 2 - raised. FV: 0 unforked; 1 - forked. DF: 0 - absence; 1 - presence 

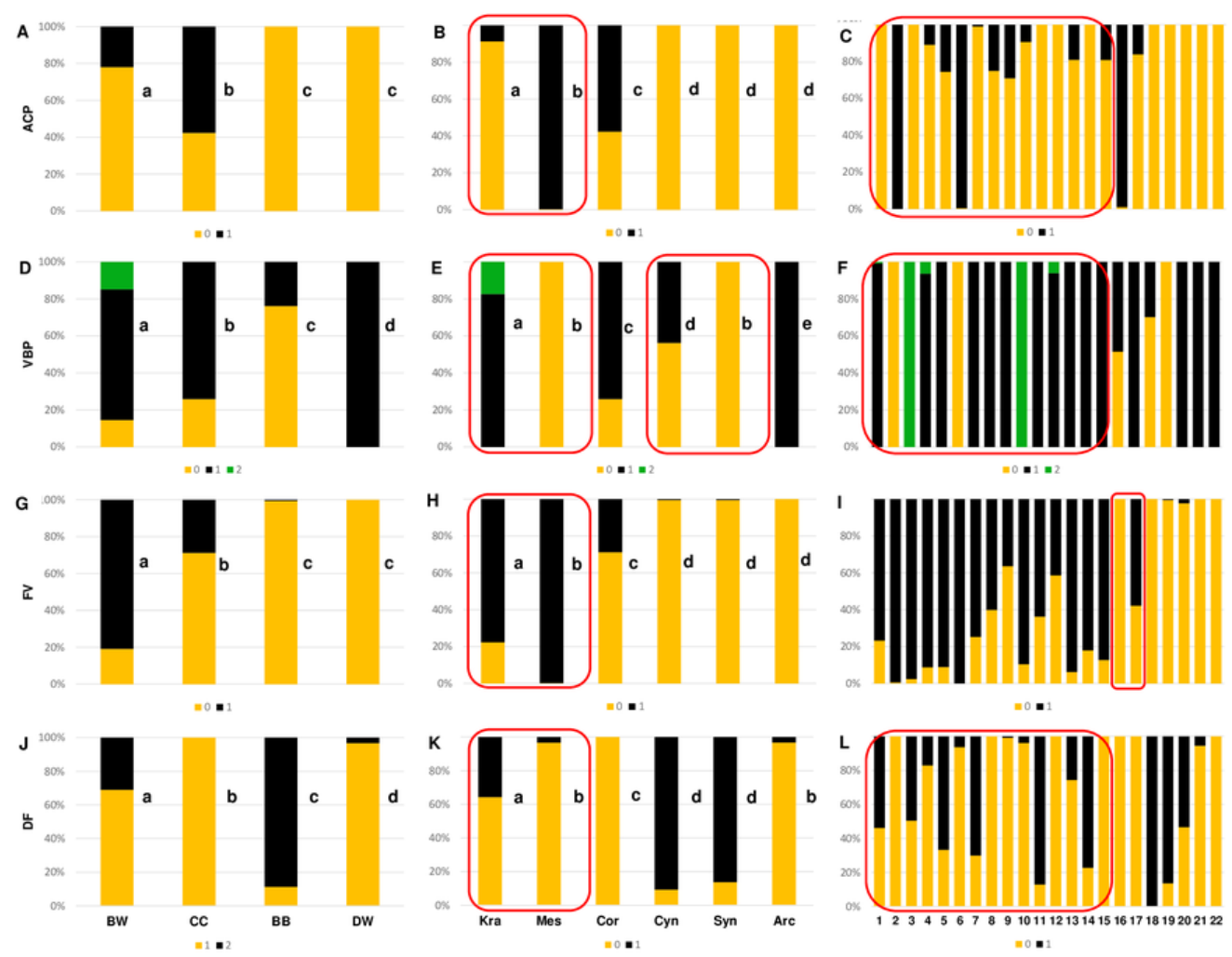
Figure 8

A scatterplot of the first two discriminant functions (CAN1, CAN2) for 22 Cornus species based on the characters of the internal structure of 317 endocarps

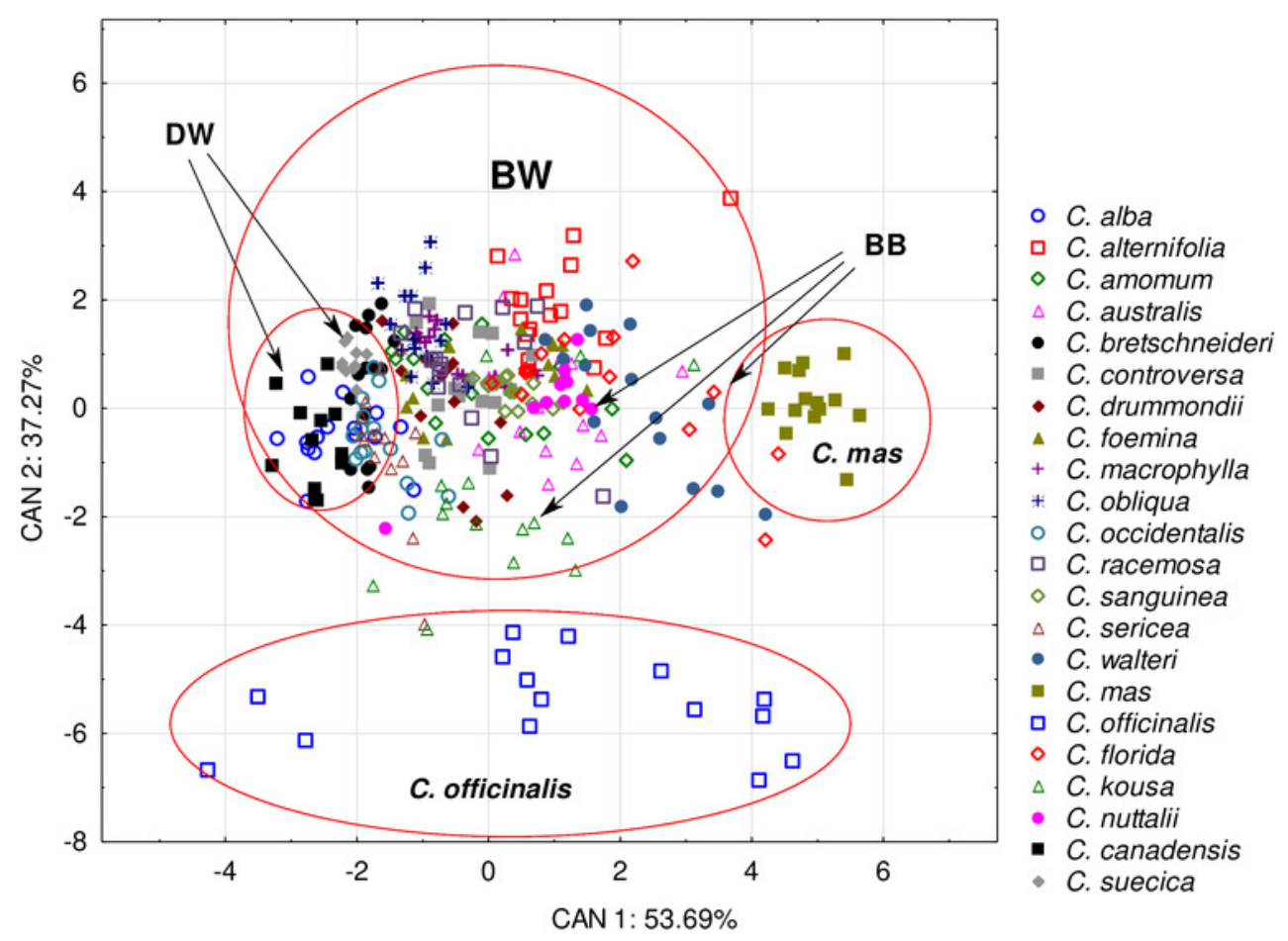




\section{Figure 9}

The median (point), the first and third quartile (box) and the minimum and maximum values (whisker) for the germination valve thickness (GVT), septum width (SMW) and WTP in Cornus species

WTP - thickness of the endocarp wall divided by the diameter of the endocarp, multiplied by 100. (A, D, G) groups; $(B, E, H)$ subgenera; $(C, F, I)$ species. Different lowercase letters indicate particular units differing in given characters. The red box marks the groups with significant differences inside (Mann-Whitney $U$ tests, $p<0.05$ ). For species description, see Table 1
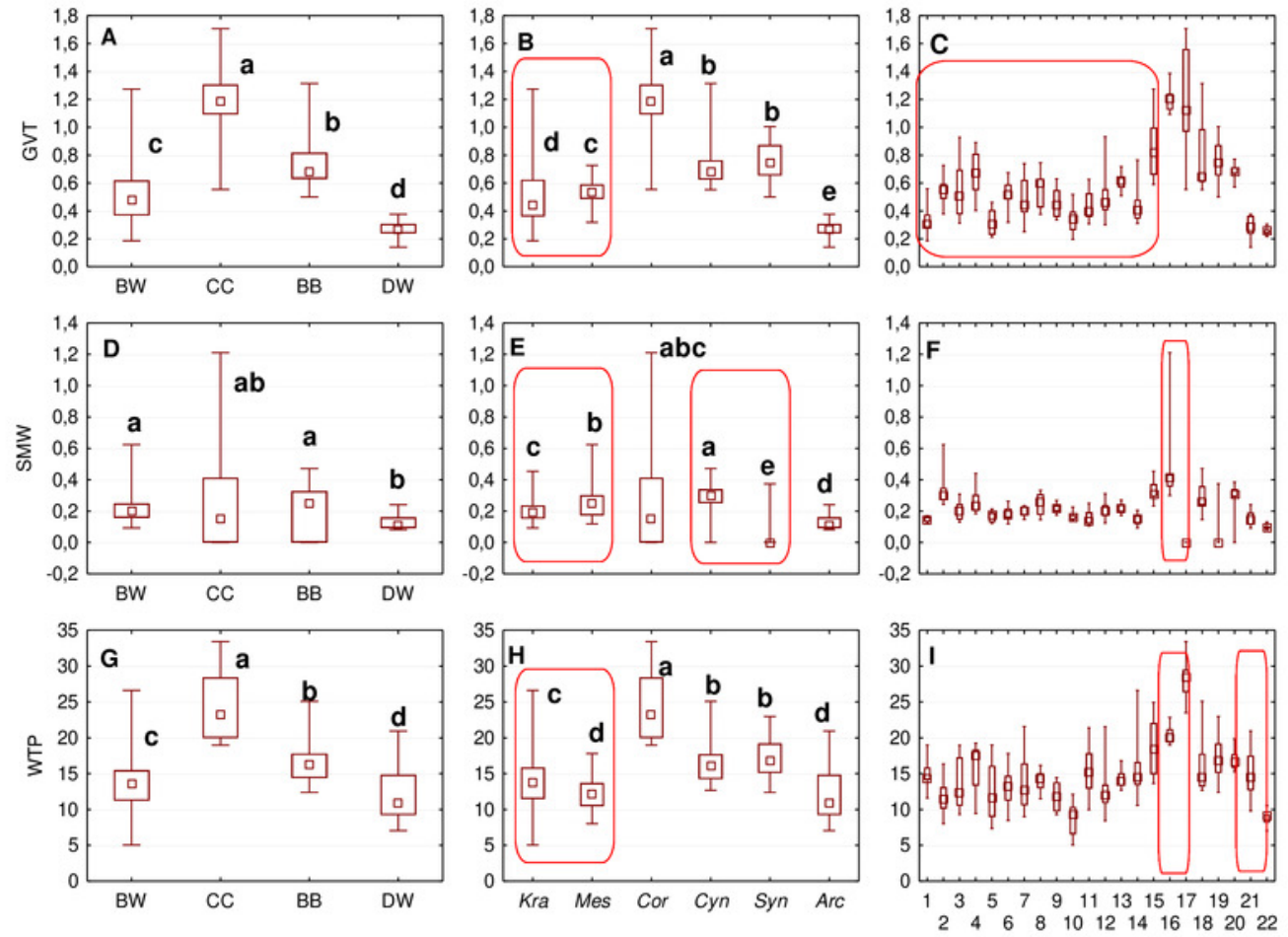
Figure 10

The median (point), the first and third quartile (box), and the minimum and maximum values (whisker) for the number of cavities in the endocarp wall (DCN) in C. mas and $C$. officinalis

The lowercase letters indicate significant differences (Mann-Whitney $U$ tests, $p<0.05$ )

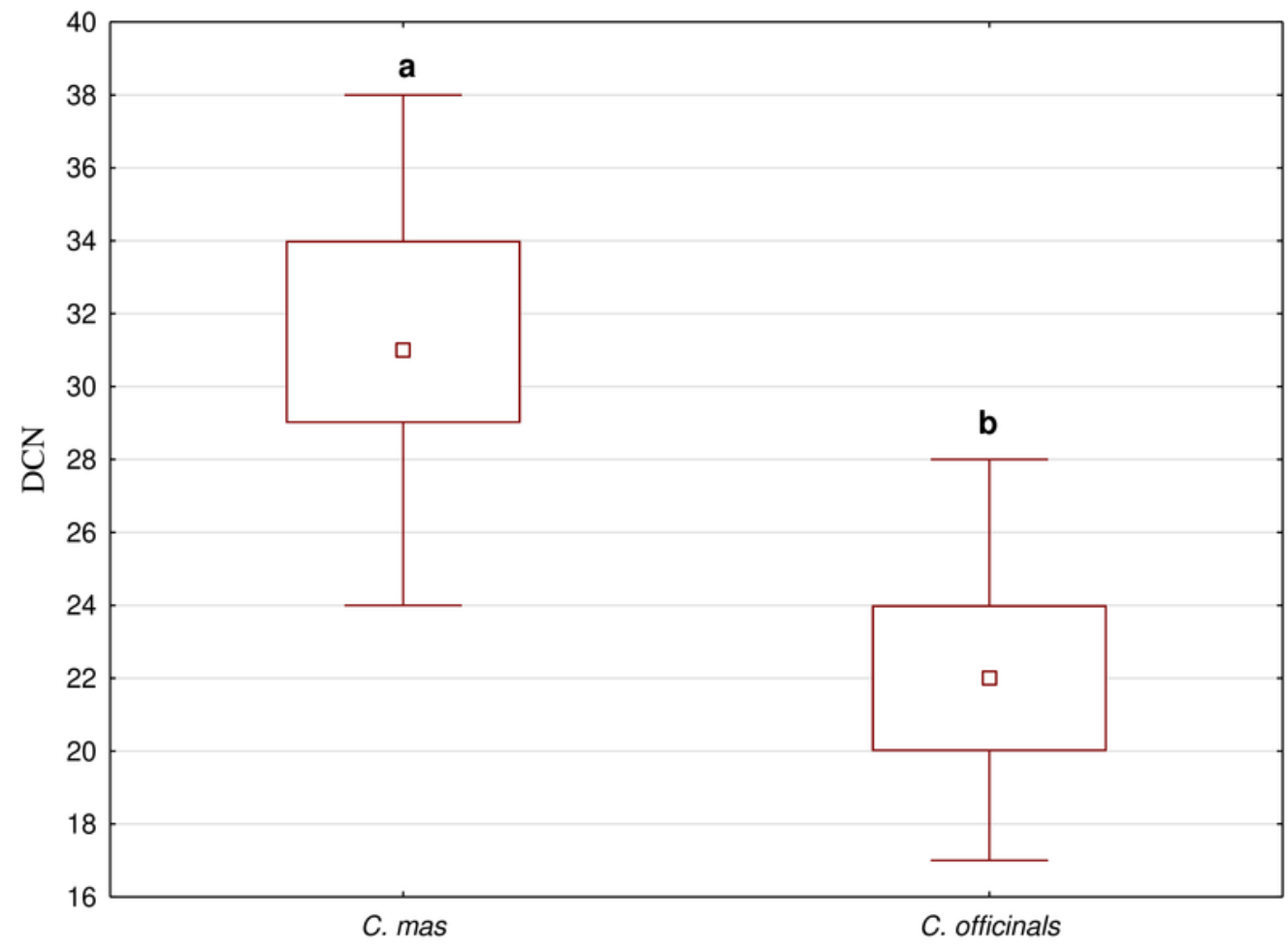




\section{Figure 11}

SEM micrographs of sections of endocarps of $C$. racemosa (A-B), C. macrophylla (C-D), C. foemina (E-F), C. walteri (G-H), C. amomum (I-J), C. obliqua (K-L), C. alternifolia (M-N), C. controversa (O-P)

(A, B) cross-sections of endocarp and septum with crystals; (C, D) longitudinal sections of endocarp and septum with crystal; (E) longitudinal section of endocarp; (F) cross-section of septum with crystals; $(G)$ cross-section of endocarp; $(H)$ longitudinal section of septum with crystal; (I) cross-section of endocarp; (J) longitudinal section of septum with crystal; (K, L) cross-sections of endocarp with crystal and septum; (M) cross-section of endocarp with crystal; (N) longitudinal section of septum; (O, P) cross-sections of endocarp and septum with crystal. C, crystals; E, endosperm; Em, embryo; S, septum; TS, transition sclereid zone; IE, inner endocarp 

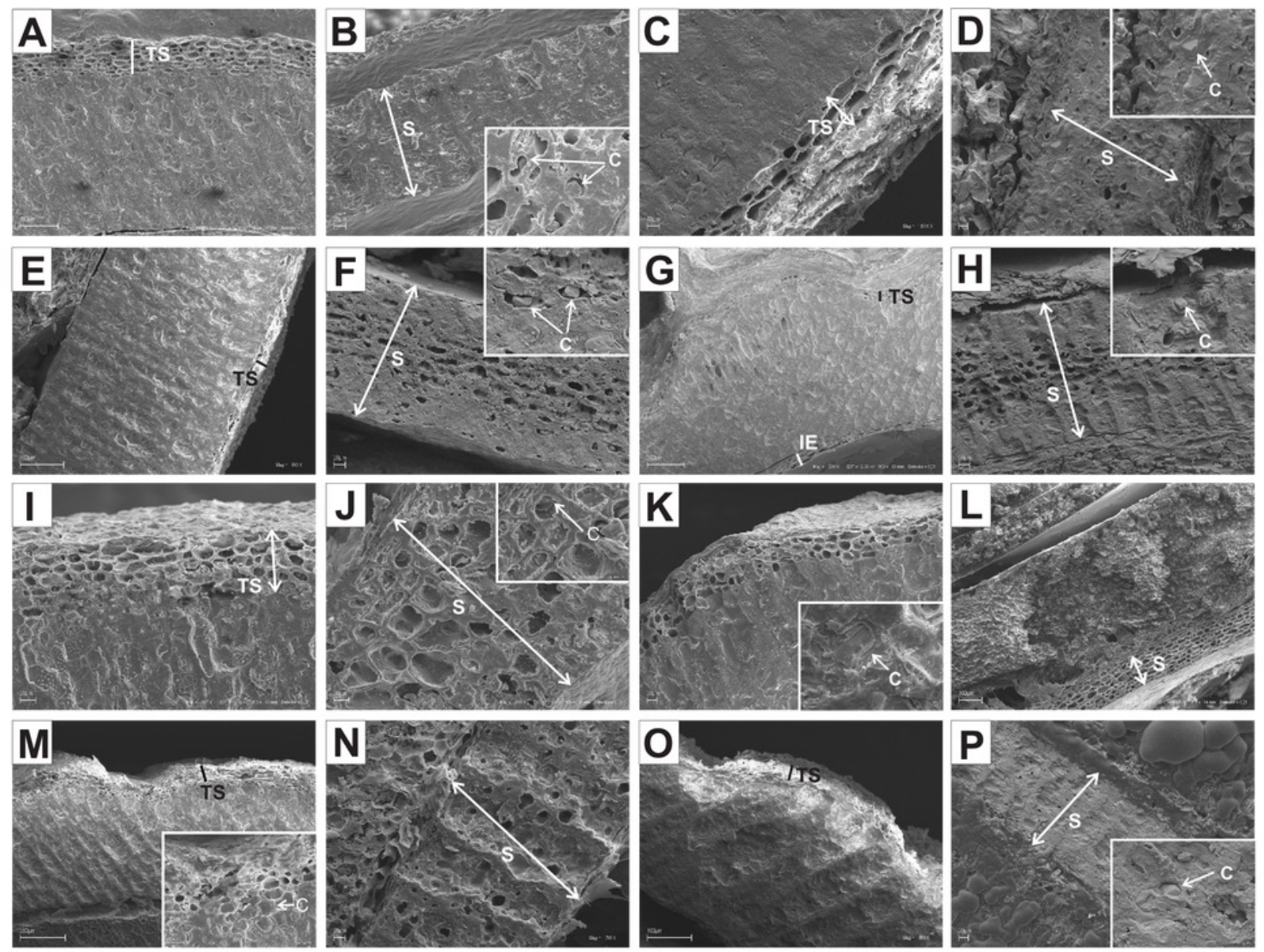


\section{Figure 12}

SEM micrographs of cross-sections and longitudinal sections of endocarps of $C$. mas (A-B), C. officinalis (C-D), C. suecica (E-F), C. canadensis (G-H), C. florida (I-J), C. nuttallii (K-L), C. kousa (M-N)

(A) cross-section of endocarp; (B) cross-section of septum, endosperm, and embryo; (C, D) longitudinal sections of endocarp with endosperm, embryo, and crystals; $(E)$ cross-section of endocarp; (F) longitudinal section of septum; (G, H) cross-sections of endocarp and septum with crystal; (I) cross-sections and longitudinal sections of endocarp with crystals; (J) crosssection of septum with crystals; $(K)$ cross-sections and longitudinal sections of endocarp with crystal; (L) longitudinal section of septum with crystals; (M) cross-section and longitudinal sections of endocarp with crystal; (N) cross-section of septum with crystals. C, crystals; E, endosperm; Em, embryo; IE, inner endocarp; OE, outer endocarp; S, septum; TS, transition sclereid zone 

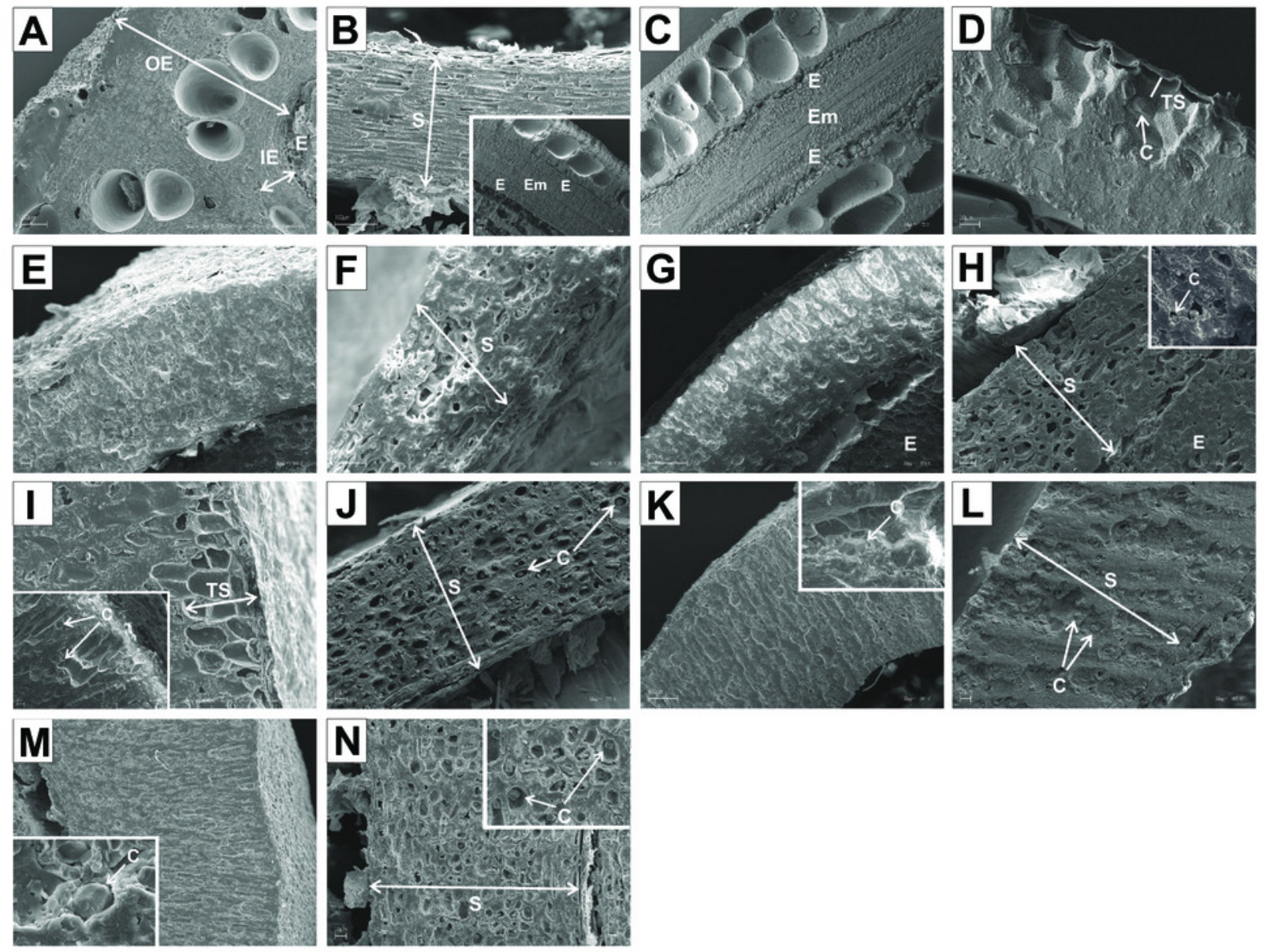


\section{Figure 13}

SEM micrographs of cross- and longitudinal sections of endocarps of $C$. alba $(A-C), C$. sericea (D-F), C. occidentalis (G-I), C. drummondii (J-L), C. bretchsneideri (M-O), C. sanguinea ( $\mathrm{P}-\mathrm{R}), \mathrm{C}$. australis $(\mathrm{S}-\mathrm{U})$

(A) cross-sections of endocarp and septum with crystal (B, C); (D, E) cross-sections of endocarp with crystal; (F) longitudinal section of septum; $(G)$ cross-section of endocarp; $(H, I)$ longitudinal sections of septum with crystal; (J, K) cross-sections of endocarp with crystals and septum (L); (M, N) cross-sections of endocarp and septum with endosperm and embryo; (O) longitudinal section of septum with crystal; (P) cross-sections of endocarp and septum with crystals $(\mathrm{Q}, \mathrm{R}) ;(\mathrm{S})$ cross-sections of endocarp and septum with endosperm and crystals (T, U). C, crystals; E, endosperm; Em, embryo; S, septum; TS, transition sclereid zone; IE, inner endocarp 

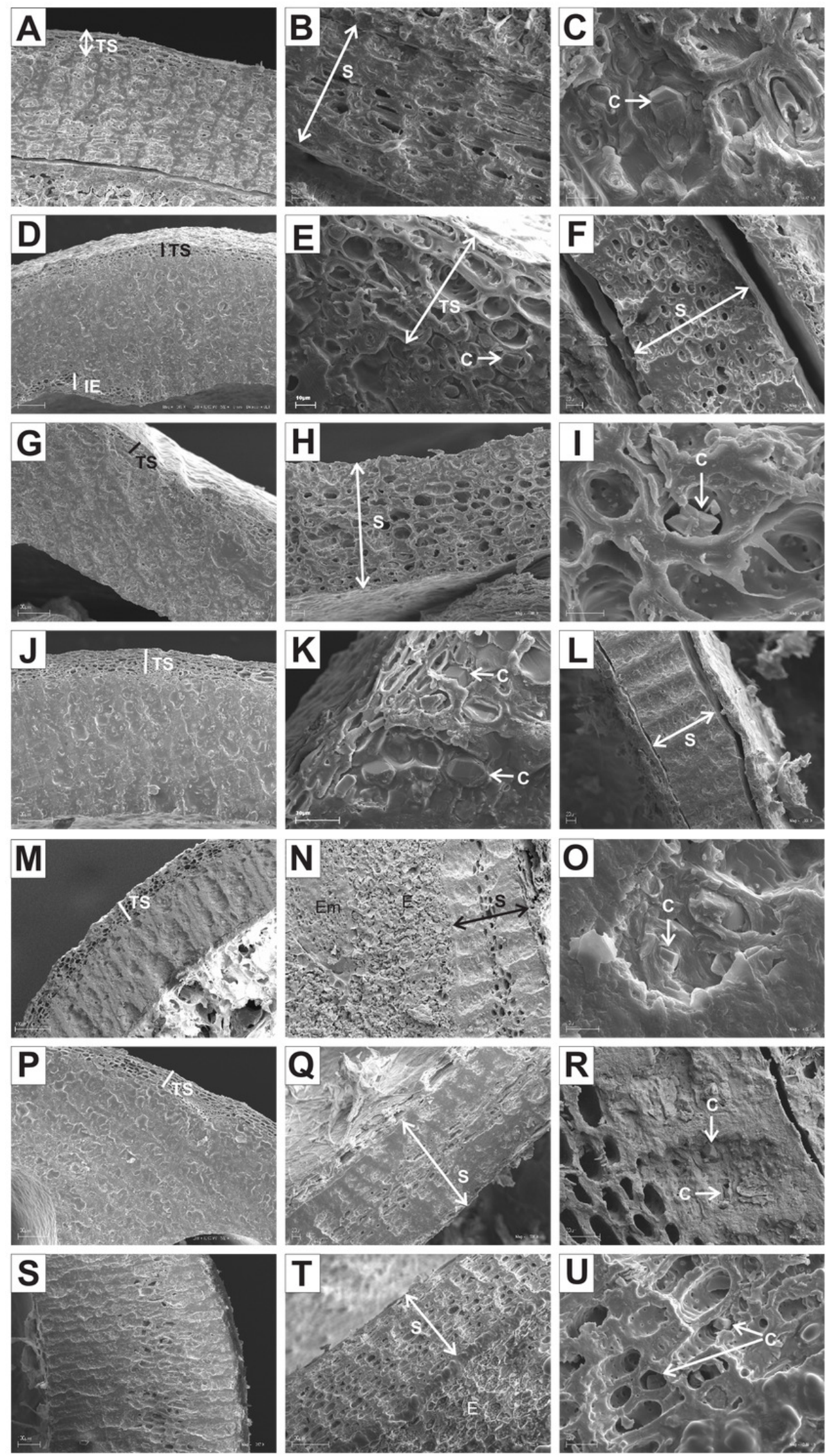


\section{Figure 14}

SEM micrographs of endocarp sculpture of Cornus alba (A-B), C. sericea (C-D), C. occidentalis (E-H), C. drummondii (I-J), C. bretschneideri (K-L), C. sanguinea (M-N), C. australis (O-P)
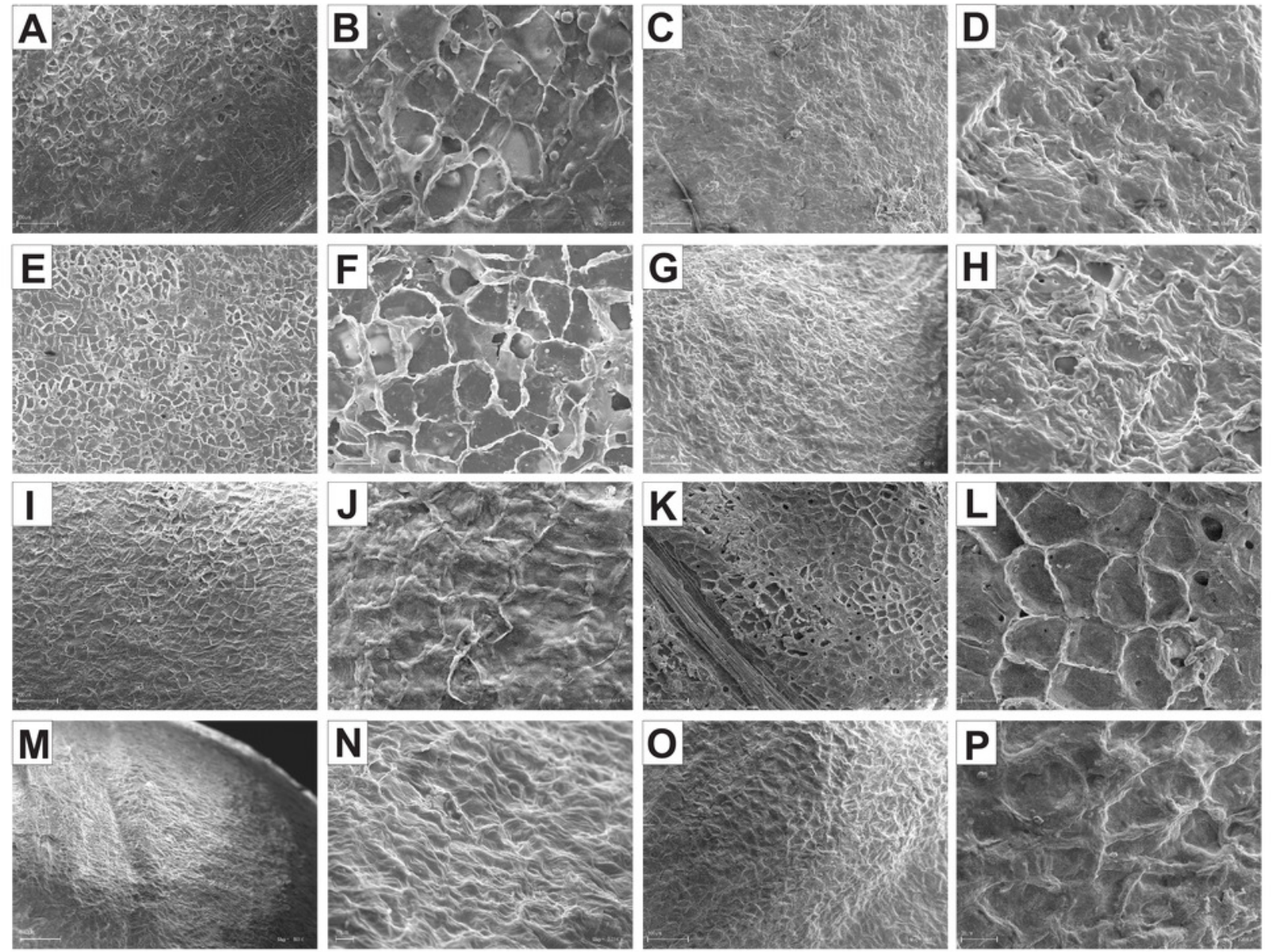


\section{Figure 15}

SEM micrographs of endocarp sculpture of Cornus racemosa (A-B), C. macrophylla (C-D), C. foemina (E-F), C. walteri (G-H), C. amomum (I-J), C. obliqua (K-L), C. alternifolia (M-N), C. controversa (O-P)
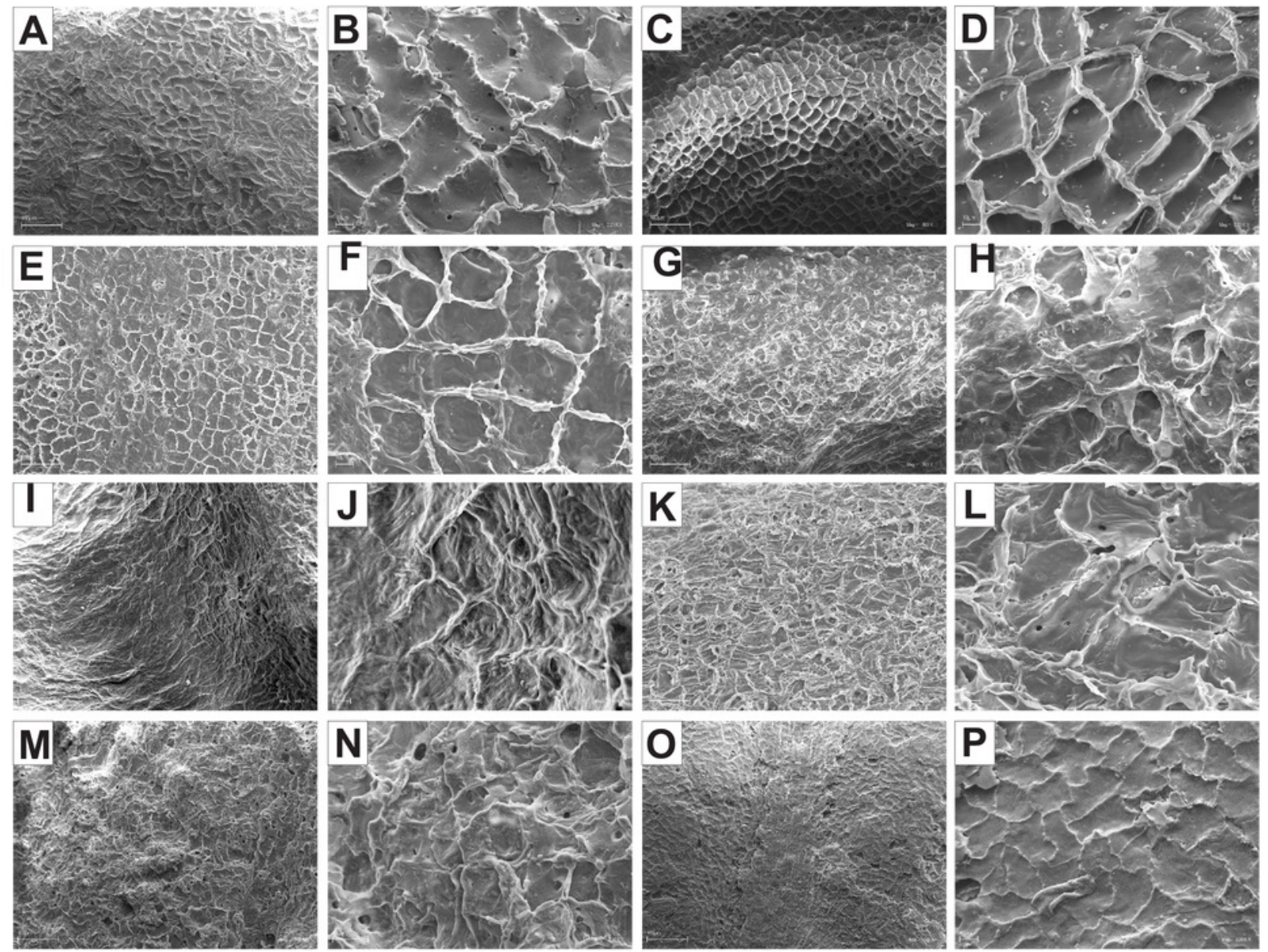


\section{Figure 16}

SEM micrographs of endocarp sculpture of Cornus mas (A-B), C. officinalis (C-D), C. suecica (E-F), C. canadensis (G-H), C. florida (I-J), C. nuttallii (K-L), C. kousa (M-N)
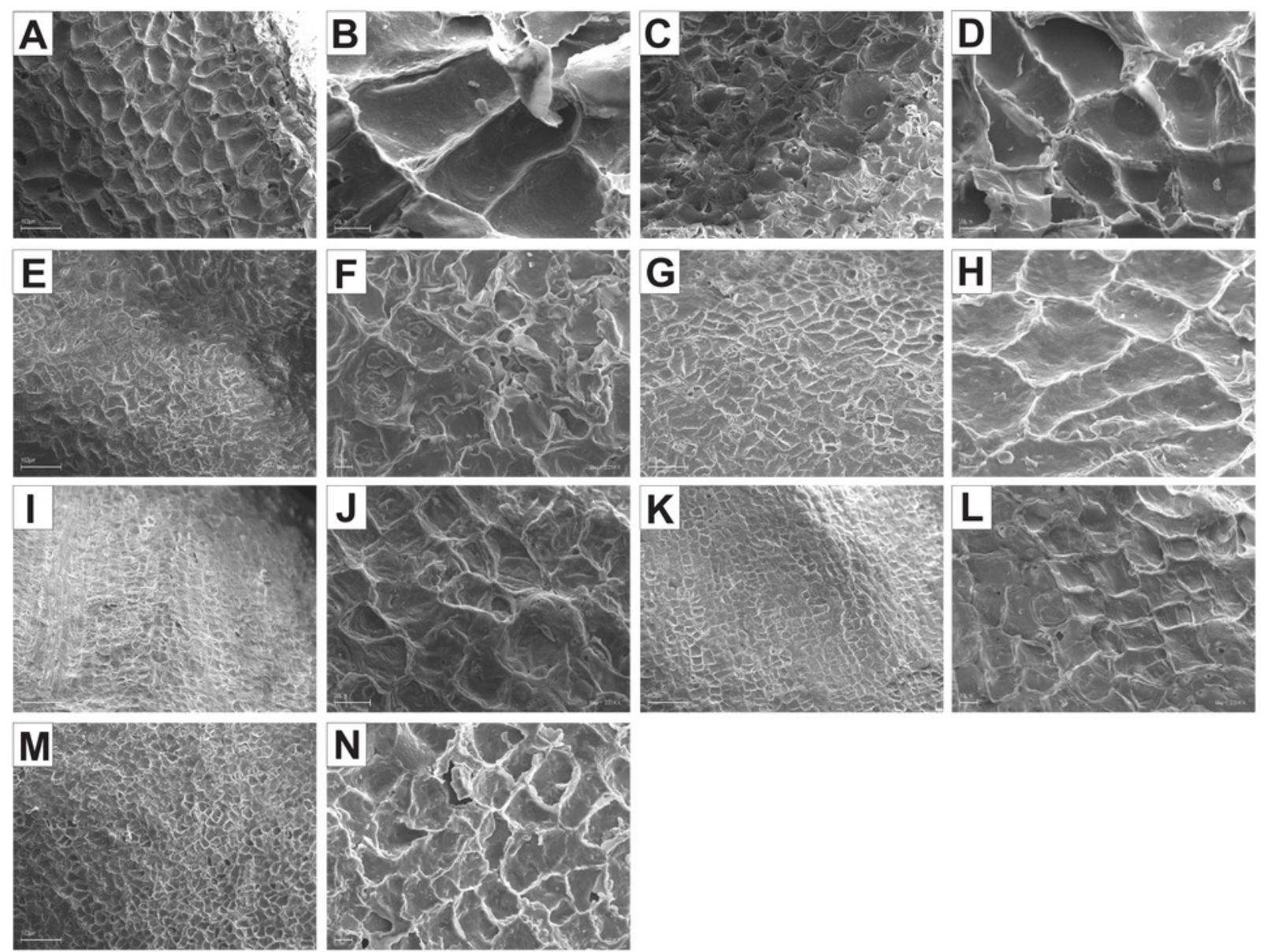


\section{Table 1 (on next page)}

List of the examined Cornus species 


\begin{tabular}{|c|c|c|c|}
\hline \multirow{2}{*}{$\begin{array}{c}\text { Species } \\
\text { No }\end{array}$} & \multirow[b]{2}{*}{ Cornus species } & \multicolumn{2}{|c|}{ Species affinity } \\
\hline & & Subgenus & $\begin{array}{l}\text { Morphological } \\
\text { group }\end{array}$ \\
\hline 1 & alba L. & Kraniopsis & $\mathrm{BW}$ \\
\hline 2 & alternifolia L.f. & Mesomora & \\
\hline 3 & amomum Mill. & Kraniopsis & \\
\hline 4 & australis C.A.Mey. & Kraniopsis & \\
\hline 5 & bretschneideri L.Henry & Kraniopsis & \\
\hline 6 & controversa Hemsl. & Mesomora & \\
\hline 7 & drummondii C.A.Mey. & Kraniopsis & \\
\hline 8 & foemina Mill. & Kraniopsis & \\
\hline 9 & macrophylla Wall. & Kraniopsis & \\
\hline 10 & obliqua Raf. & Kraniopsis & \\
\hline 11 & occidentalis (Torr. \& A.Gray) Coville & Kraniopsis & \\
\hline 12 & racemosa Lam. & Kraniopsis & \\
\hline 13 & sanguinea $\mathrm{L}$. & Kraniopsis & \\
\hline 14 & sericea $\mathrm{L}$. & Kraniopsis & \\
\hline 15 & walteri Wangerin & Kraniopsis & \\
\hline 16 & mas L. & Cornus & $\mathrm{CC}$ \\
\hline 17 & officinalis Siebold \& Zucc. & Cornus & \\
\hline 18 & florida $\mathrm{L}$ & Cynoxylon & $\mathrm{BB}$ \\
\hline 19 & kousa F.Buerger ex Hance & Syncarpea & \\
\hline 20 & nuttallii Audubon ex Torr. \& A.Gray & Cynoxylon & \\
\hline 21 & canadensis $\mathrm{L}$. & Arctocrania & DW \\
\hline 22 & suecica $\mathrm{L}$. & Arctocrania & \\
\hline
\end{tabular}


Table 2 (on next page)

The qualitative and quantitative characters examined in the morphometric analyses of Cornus endocarps 


\begin{tabular}{llccc}
\hline No. & Description & $\begin{array}{c}\text { Character } \\
\text { abbreviation }\end{array}$ & $\begin{array}{c}\text { Type of character: } \\
\text { continuous (C) } \\
\text { discrete (D) }\end{array}$ & $\begin{array}{c}\text { Units of } \\
\text { measurement/ } \\
\text { coding }\end{array}$ \\
\hline 1 & Endocarp length & $\mathrm{SL}$ & $\mathrm{C}$ & $\mathrm{mm}$ \\
2 & Endocarp thickness & $\mathrm{ST}$ & $\mathrm{C}$ & $\mathrm{mm}$ \\
3 & Endocarp width & $\mathrm{SW}$ & $\mathrm{C}$ & $\mathrm{mm}$ \\
4 & Endocarp length-to-width ratio & $\mathrm{SL} / \mathrm{SW}$ & $\mathrm{C}$ & \\
5 & Endocarp width -to-thickness ratio & $\mathrm{SW} / \mathrm{ST}$ & $\mathrm{C}$ & \\
6 & Number of vascular bundles on endocarp surface & $\mathrm{VN}$ & $\mathrm{C}$ & $\mathrm{m}$ \\
7 & Share of forked vascular bundles & $\mathrm{FV} \%$ & $\mathrm{C}$ & $\mathrm{mm}$ \\
8 & Apical cavity length & $\mathrm{ACL}$ & $\mathrm{C}$ & $0-2$ \\
9 & Apical cavity width & $\mathrm{ACW}$ & $\mathrm{C}$ & $0-3$ \\
10 & Endocarp shape in vertical projection & $\mathrm{SSH}$ & $\mathrm{D}$ & $0-3$ \\
11 & Apical shape & $\mathrm{ASH}$ & $\mathrm{D}$ & $0-1$ \\
12 & Basal shape & $\mathrm{BSH}$ & $\mathrm{D}$ & $0-1$ \\
13 & Smooth/rough endocarp surface & $\mathrm{SSF}$ & $\mathrm{D}$ & $0-2$ \\
14 & Absence/presence of apical cavity & $\mathrm{ACP}$ & $\mathrm{D}$ & $0-1$ \\
15 & Position of vascular bundles on endocarp surface & $\mathrm{VBP}$ & $\mathrm{D}$ & $0-1$ \\
16 & Absence/presence of forked vascular bundles & $\mathrm{FV}$ & $\mathrm{D}$ & \\
17 & Absence/presence of distinctive furrow & $\mathrm{DF}$ & $\mathrm{D}$ & \\
\hline
\end{tabular}


Table 3 (on next page)

The quantitative characters of the internal structure of Cornus endocarps 


\begin{tabular}{|c|c|c|c|c|}
\hline No. & Description & $\begin{array}{c}\text { Character } \\
\text { abbreviation }\end{array}$ & $\begin{array}{l}\text { Type of character: } \\
\text { continuous (C) } \\
\text { discrete (D) }\end{array}$ & $\begin{array}{c}\text { Units of } \\
\text { measurement }\end{array}$ \\
\hline 1 & Germination valve thickness & GVT & $\mathrm{C}$ & $\mathrm{mm}$ \\
\hline 2 & Septum width & SMW & $\mathrm{C}$ & $\mathrm{mm}$ \\
\hline 3 & $\begin{array}{l}\text { Thickness of endocarp wall } \\
\text { (germination valve) divided by } \\
\text { endocarp diameter or multiplied by } \\
100\end{array}$ & WTP & $\mathrm{C}$ & $\%$ \\
\hline 4 & Number of cavities in endocarp wall & $\mathrm{DCN}$ & $\mathrm{D}$ & \\
\hline
\end{tabular}




\section{Table 4 (on next page)}

The average factor loadings of the groups in the PCA for a sample of 254 Cornus specimens 


\begin{tabular}{|l|r|r|r|}
\hline \multicolumn{1}{|c|}{ Groups } & \multicolumn{1}{c|}{ Axis 1 } & Axis 2 & Axis 3 \\
\hline DW & 3.46 & -1.10 & 1.98 \\
\hline BW & -0.21 & 0.91 & -0.19 \\
\hline CC & -2.06 & -3.57 & -0.06 \\
\hline BB & 0.25 & -2.65 & -0.31 \\
\hline
\end{tabular}

1 


\section{Table 5 (on next page)}

The PCA results for nine quantitative characters of the Cornus endocarps representing 22 species from four groups

Strong correlations $(r \geq 0.6)$ marked in bold. For a description of the characters, see Table 2 


\begin{tabular}{lccc}
\hline PCA axis: & $\mathrm{V} 1$ & $\mathrm{~V} 2$ & $\mathrm{~V} 3$ \\
Eigenvalues: & 3.16 & 2.88 & 1.33 \\
\hline Character & Component loadings \\
\hline SL & -0.57 & $\mathbf{- 0 . 7 0}$ & -0.20 \\
ST & $\mathbf{- 0 . 8 3}$ & -0.24 & -0.42 \\
SW & $\mathbf{- 0 . 8 3}$ & 0.09 & -0.41 \\
SL/SW & -0.10 & $\mathbf{- 0 . 9 0}$ & 0.06 \\
SW/ST & 0.20 & 0.53 & 0.10 \\
VN & -0.24 & $\mathbf{0 . 8 5}$ & -0.29 \\
FV\% & -0.46 & $\mathbf{0 . 6 9}$ & -0.17 \\
ACL & $\mathbf{- 0 . 7 6}$ & 0.11 & $\mathbf{0 . 6 4}$ \\
ACW & $\mathbf{- 0 . 7 5}$ & 0.15 & $\mathbf{0 . 6 4}$ \\
\hline Total variance explain. \% & 35.08 & 31.98 & 14.74 \\
Cumul. total variance explain. \% & 35.08 & 66.25 & 77.95 \\
\hline
\end{tabular}




\section{Table 6(on next page)}

The results of the chi-square test of independence between the qualitative characters of the Cornus endocarps and the affinity of the specimens to groups, subgenera, and species, $\mathrm{N}=3,846$

For a description of the characters, see Table 2 


\begin{tabular}{|c|c|c|c|c|c|c|c|c|c|}
\hline \multirow{2}{*}{ Character } & \multicolumn{3}{|c|}{ Group } & \multicolumn{3}{|c|}{ Subgenus } & \multicolumn{3}{|c|}{ Species } \\
\hline & $d f$ & $\mathrm{Chi}^{2}$ & $p$ & $d f$ & $\mathrm{Chi}^{2}$ & $p$ & $d f$ & $\mathrm{Chi}^{2}$ & $p$ \\
\hline $\mathrm{SSH}$ & 9 & 2405.31 & 0.00 & 15 & 5209.32 & 0.00 & 63 & 8567.18 & 0.00 \\
\hline $\mathrm{ASH}$ & 9 & 1652.95 & 0.00 & 15 & 1921.87 & 0.00 & 63 & 5072.13 & 0.00 \\
\hline $\mathrm{BSH}$ & 9 & 361.07 & 0.00 & 15 & 837.07 & 0.00 & 63 & 2493.70 & 0.00 \\
\hline SSF & 3 & 260.74 & 0.00 & 5 & 763.87 & 0.00 & 21 & 2868.97 & 0.00 \\
\hline $\mathrm{ACP}$ & 3 & 474.17 & 0.00 & 5 & 2166.57 & 0.00 & 21 & 2706.49 & 0.00 \\
\hline VBP & 6 & 1001.28 & 0.00 & 10 & 3196.48 & 0.00 & 42 & 6852.60 & 0.00 \\
\hline FV & 3 & 1641.09 & 0.00 & 5 & 1714.26 & 0.00 & 21 & 2190.12 & 0.00 \\
\hline DF & 3 & 881.36 & 0.00 & 30 & 1048.30 & 0.00 & 21 & 2101.29 & 0.00 \\
\hline
\end{tabular}




\section{Table 7 (on next page)}

The list of uniform qualitative characters of Cormus endocarps within groups, subgenera, and species 


\begin{tabular}{|c|c|c|c|}
\hline Character & Group & Subgenus & Species \\
\hline $\mathrm{SSH}$ & CC - spherical & $\left.\begin{array}{l}\text { Cornus - spherical } \\
\text { Cynoxylon - spherical } \\
\text { Syncarpea - irregular }\end{array}\right\} \underbrace{\mathrm{CC}}$ & 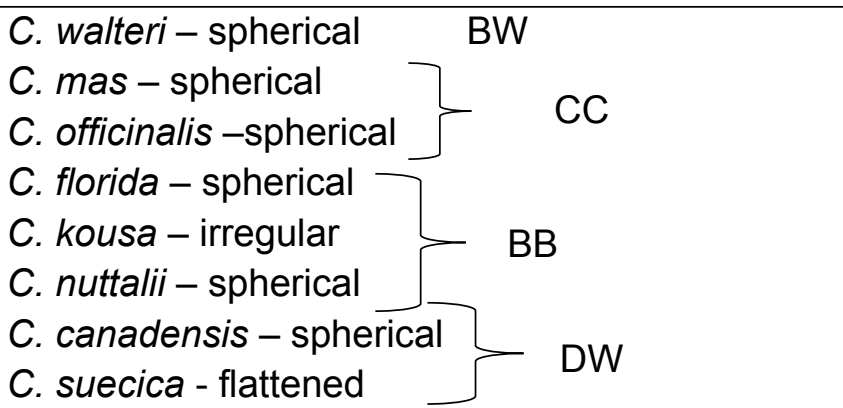 \\
\hline $\mathrm{ASH}$ & $\mathrm{CC}-$ rounded or truncate & $\begin{array}{ll}\text { Mesomora - rounded or truncate } & \text { BW } \\
\text { Cornus - rounded or truncate } & \text { CC }\end{array}$ & $\left.\begin{array}{l}\text { C. alternifolia - rounded or truncate } \\
\text { C. controversa - rounded or truncate } \\
\text { C. macrophylla - rounded or truncate } \\
\text { C. mas - rounded or truncate } \\
\text { C. officinalis - rounded or truncate } \\
\text { C. canadensis - acuminate }\end{array}\right\}$ BW \\
\hline $\mathrm{BSH}$ & - & - & $\begin{array}{lc}\text { C. macrophylla - rounded } & \text { BW } \\
\text { C. officinalis - rounded } & \text { CC } \\
\text { C. canadensis - rounded } & \text { DW }\end{array}$ \\
\hline SSF & $\begin{array}{l}\text { CC - smooth } \\
\text { DW - smooth }\end{array}$ & $\begin{array}{l}\text { Cornus - smooth } \\
\text { Cynoxylon - smooth } \\
\text { Arctocrania - smooth }\end{array}$ & 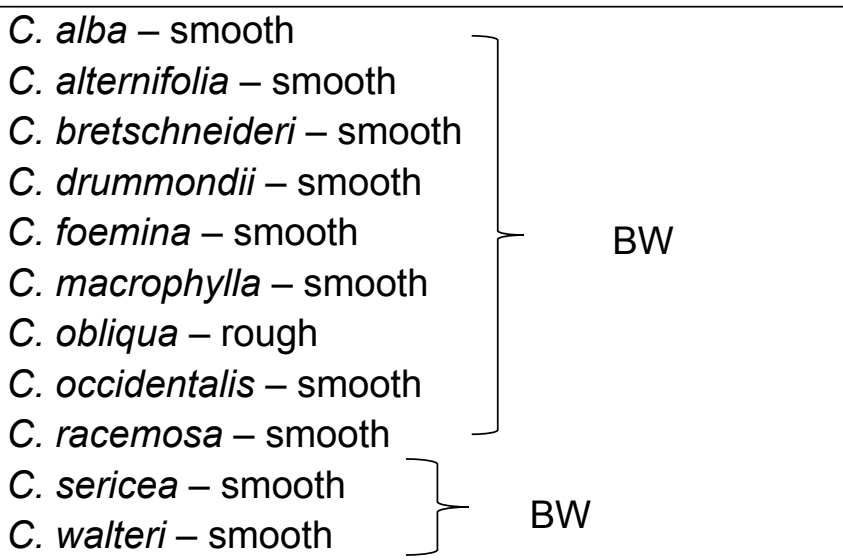 \\
\hline
\end{tabular}




\begin{tabular}{|c|c|c|c|c|c|c|}
\hline & & & & $\left.\begin{array}{l}\text { C. mas - smooth } \\
\text { C. officinalis - smooth } \\
\text { C. florida - smooth } \\
\text { C. nuttalii - smooth } \\
\text { C. canadensis - smooth } \\
\text { C. suecica - smooth }\end{array}\right\}$ & $\begin{array}{l}\mathrm{CC} \\
\mathrm{BB}\end{array}$ & DW \\
\hline VBP & DW - flat & $\begin{array}{l}\text { Mesomora - sunken } \\
\text { Syncarpea - sunken } \\
\text { Arctocrania - flat }\end{array}$ & $\begin{array}{l}\text { BW } \\
\text { BB } \\
\text { DW }\end{array}$ & $\left.\begin{array}{l}\text { C. alternifolia - sunken } \\
\text { C. amomum - raised } \\
\text { C. bretschneideri - flat } \\
\text { C. controversa - sunken } \\
\text { C. drummondii - flat } \\
\text { C. foemina - flat } \\
\text { C. macrophylla - flat } \\
\text { C. obliqua - raised } \\
\text { C. occidentalis - flat } \\
\text { C. sanguinea - flat } \\
\text { C. sericea - flat } \\
\text { C. walteri - flat } \\
\text { C. officinalis - flat } \\
\text { C. kousa - sunken } \\
\text { C. nuttalii - flat } \\
\text { C. canadensis - flat } \\
\text { C. suecica - flat }\end{array}\right\}$ & ]$_{B W}$ & DW \\
\hline FV & $\begin{array}{l}\text { BB - unforked } \\
\text { DW - unforked }\end{array}$ & $\begin{array}{l}\text { Mesomora - forked } \\
\text { Cynoxylon - unforked } \\
\text { Arctocrania - unforked }\end{array}$ & $\begin{array}{l}\text { BW } \\
\text { BB } \\
\text { DW }\end{array}$ & $\begin{array}{l}\text { C. controversa - forked } \\
\text { C. mas - unforked CC } \\
\text { C. florida - unforked } \\
\text { C. canadensis - unforked } \\
\text { C. suecica - unforked }\end{array}$ & $\begin{array}{l}\text { BW } \\
\text { BB } \\
\end{array}$ & DW \\
\hline DF & CC-absence & Cornus - absence & $\mathrm{CC}$ & $\left.\begin{array}{l}\text { C. alternifolia - absence } \\
\text { C. foemina - absence } \\
\text { C. racemosa - absence } \\
\text { C. walteri - absence }\end{array}\right\}$ & $\begin{array}{l}\text { BW } \\
\text { BW }\end{array}$ & \\
\hline
\end{tabular}




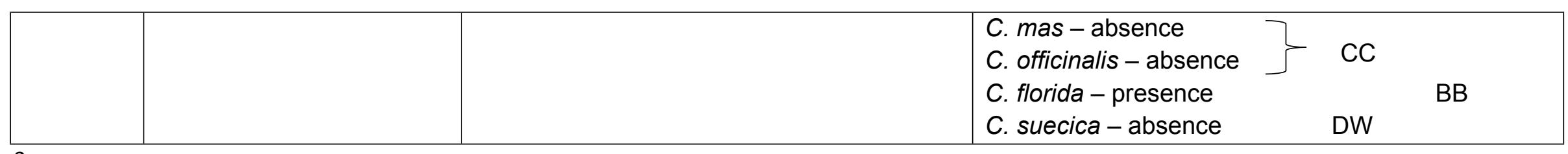


Table 8(on next page)

Similarity coefficients calculated for Cornus groups based on quantitative and qualitative characters of endocarps

The highest coefficients are bolded 


\begin{tabular}{|c|c|c|c|c|c|c|c|c|c|c|c|c|}
\hline & \multicolumn{4}{|c|}{$\begin{array}{l}\text { Quantitative characters } \\
\qquad(\mathrm{N}=8)\end{array}$} & \multicolumn{4}{|c|}{$\begin{array}{l}\text { Qualitative characters } \\
\qquad(\mathrm{N}=8)\end{array}$} & \multicolumn{4}{|c|}{$\begin{array}{l}\text { All morphological } \\
\text { characters }(\mathrm{N}=16)\end{array}$} \\
\hline & BW & $\mathrm{CC}$ & BB & DW & BW & $\mathrm{CC}$ & $\mathrm{BB}$ & $\mathrm{DW}$ & BW & $\mathrm{CC}$ & $\mathrm{BB}$ & DW \\
\hline BW & 1.00 & & & & 1.00 & & & & 1.00 & & & \\
\hline $\mathrm{CC}$ & 0.18 & 1.00 & & & 0.16 & 1.00 & & & 0.17 & 1.00 & & \\
\hline $\mathrm{BB}$ & 0.16 & 0.46 & 1.00 & & 0.15 & 0.42 & 1.00 & & 0.15 & 0.44 & 1.00 & \\
\hline DW & 0.00 & 0.17 & 0.71 & 1.00 & 0.08 & 0.45 & 0.36 & 1.00 & 0.04 & 0.31 & 0.54 & 1.00 \\
\hline
\end{tabular}

1 


\section{Table 9 (on next page)}

Canonical discriminant function (CDA), the discriminatory power and correlations with the discriminant functions of three characters of the internal structure of Cornus endocarps

For a description of the characters, see Table 3 


\begin{tabular}{|c|c|c|c|c|}
\hline \multirow[b]{2}{*}{ Character } & \multirow{2}{*}{$\begin{array}{l}\text { Wilk's } \\
\text { lambda }\end{array}$} & \multirow{2}{*}{$\begin{array}{l}\text { Partial } \\
\text { lambda }\end{array}$} & \multicolumn{2}{|c|}{$\begin{array}{c}\text { Factor structure } \\
\text { coefficients }\end{array}$} \\
\hline & & & CAN1 & CAN2 \\
\hline GVT & 0.12 & 0.39 & 0.84 & -0.54 \\
\hline SMW & 0.10 & 0.46 & 0.50 & 0.55 \\
\hline WTP & 0.10 & 0.48 & 0.41 & -0.79 \\
\hline Eigenvalues & - & - & 3.2 & 2.24 \\
\hline Total variance explain. $\%$ & - & - & 53.69 & 37.27 \\
\hline Cumul. total variance explain. $\%$ & - & - & 53.69 & 90.96 \\
\hline
\end{tabular}




\section{Table $\mathbf{1 0}$ (on next page)}

The results of the Kruskal-Wallis tests $(H)$ between the characters of internal structure of dogwood endocarps assigned to the group, subgenus, and species

For a description of the characters, see Table 3 


\begin{tabular}{lllll}
\hline Taxonomic unit & Character & $H$ & $d f$ & $p$ \\
\hline \multirow{3}{*}{ Group } & GVT & 143.82 & & 0.00 \\
& SMW & 22.42 & 3 & 0.00 \\
& WTP & 97.91 & & 0.00 \\
Subgenus & GVT & 145.60 & & 0.00 \\
& SMW & 64.02 & 5 & 0.00 \\
& WTP & 102.43 & & 0.00 \\
Species & GVT & 231.27 & & 0.00 \\
& SMW & 218.48 & 21 & 0.00 \\
& WTP & 178.59 & & 0.00
\end{tabular}

1 


\section{Table $\mathbf{1 1}$ (on next page)}

The internal structure characters of the endocarps of 22 Cornus species under study

* - the septum with a secretory cavity 


\begin{tabular}{|c|c|c|c|c|c|c|c|c|c|c|c|}
\hline \multirow[t]{3}{*}{ Species } & \multicolumn{3}{|c|}{ Outer endocarp (OE) } & \multicolumn{2}{|c|}{ Inner endocarp (IE) } & \multicolumn{2}{|c|}{ Transition sclereids (S) } & \multicolumn{4}{|c|}{ Septum structure (S) } \\
\hline & \multicolumn{2}{|c|}{ sclereids } & \multirow[t]{2}{*}{ crystals } & \multirow{2}{*}{ absent } & \multirow[t]{2}{*}{ present } & \multirow[t]{2}{*}{ absent } & \multirow{2}{*}{$\begin{array}{c}\text { present } \\
\text { (number of cell layers) }\end{array}$} & \multirow[t]{2}{*}{ solid } & \multirow{2}{*}{ openwork } & \multirow{2}{*}{ partly openwork } & \multirow{2}{*}{ crystals } \\
\hline & isodiametric & elongated & & & & & & & & & \\
\hline \multicolumn{12}{|c|}{ BW } \\
\hline C. alba & + & & & + & & & $+(2-3)$ & & & + & + \\
\hline A. alternifolia & + & & + & + & & & $+(3-4)$ & & & + & + \\
\hline C. атотит & + & & & + & & & $+(3-4)$ & & + & & + \\
\hline C. australis & + & & + & + & & & $+(3-4)$ & & & + & + \\
\hline C. bretchsneideri & + & & & + & & & $+(4-5)$ & & & + & + \\
\hline C. controversa & + & & & + & & & $+(1-1)$ & + & & & + \\
\hline C. drummondii & + & & + & + & & & $+(5-6)$ & + & & & + \\
\hline C. foemina & + & & & + & & & $+(2-3)$ & & & + & + \\
\hline C. macrophylla & + & & & + & & & $+(2-3)$ & + & & & + \\
\hline C. obliqua & + & & & + & & & $+(3-4)$ & & + & & + \\
\hline C. occidentalis & + & & & + & & & $+(2-3)$ & & + & & + \\
\hline C. racemosa & + & & & + & & & $+(5-7)$ & + & & W & + \\
\hline C. sanguinea & + & & & + & & & $+(2-4)$ & & & + & + \\
\hline C. sericea & + & & + & & + & & $+(3-5)$ & & & + & \\
\hline C. walteri & + & + & & & + & & $+(1-2)$ & & & + & + \\
\hline \multicolumn{12}{|c|}{$\mathrm{CC}$} \\
\hline C. mas & + & + & & & + & + & & $+^{*}$ & & & \\
\hline C. officinalis & + & + & & & + & & $+(1-1)$ & & & & \\
\hline \multicolumn{12}{|c|}{ BB } \\
\hline C. florida & + & + & & + & & & $+(2-3)$ & & + & & + \\
\hline C. kousa & + & + & & + & & + & & & & + & + \\
\hline C. nuttallii & + & + & & + & & & $+(1-1)$ & + & & & + \\
\hline \multicolumn{12}{|c|}{ DW } \\
\hline C. canadensis & + & & & + & & + & & & & + & + \\
\hline C. suecica & + & & & + & & + & & & & + & \\
\hline
\end{tabular}




\section{Table 12 (on next page)}

The micromorphology of the endocarp surface of 22 Cornus species under study 


\begin{tabular}{|c|c|c|c|c|c|c|c|c|c|c|c|}
\hline \multirow[t]{2}{*}{ Species } & \multirow{2}{*}{$\begin{array}{l}\text { Cellular } \\
\text { pattern }\end{array}$} & \multicolumn{4}{|c|}{ Cell outline } & \multicolumn{3}{|c|}{ Anticlinal cell wall boundary } & \multicolumn{3}{|c|}{ Outer periclinal cel wall } \\
\hline & & tetragonal & polygonal & rounded & irregular & raised & straight & undulate & concave & flat & Secondary sculpture \\
\hline \multicolumn{12}{|c|}{ BW } \\
\hline C. alba & reticulate & & + & & & + & + & & & + & \\
\hline A. alternifolia & reticulate & & + & & & + & + & & & + & \\
\hline C. amoтит & reticulate & & + & + & & + & & & & + & striate \\
\hline C. australis & reticulate & & + & + & & + & + & & + & & punctate \\
\hline C. bretchsneideri & reticulate & & + & & & + & + & & + & & \\
\hline C. controversa & reticulate & & & & + & + & & + & & + & \\
\hline C. drummondii & reticulate & & + & & & + & + & & & + & verrucose \\
\hline C. foemina & reticulate & & + & & & + & + & & & + & \\
\hline C. macrophylla & reticulate & & + & & & + & + & & & + & \\
\hline C. obliqua & reticulate & & + & & & + & + & & + & & \\
\hline C. occidentalis & reticulate & & + & & & + & + & & + & & verrucose \\
\hline C. racemosa & reticulate & & & & + & + & & + & + & & \\
\hline C. sanguinea & reticulate & & + & + & & + & + & & + & & striate \\
\hline C. sericea & reticulate & & + & + & & + & + & & + & & verrucose \\
\hline C. walteri & reticulate & & + & + & & + & + & & & + & \\
\hline \multicolumn{12}{|c|}{$\mathrm{CC}$} \\
\hline C.mas & reticulate & & + & + & & + & + & & + & & \\
\hline C. officinalis & reticulate & & + & + & & + & + & & + & & \\
\hline \multicolumn{12}{|c|}{ BB } \\
\hline C. florida & reticulate & + & & & & + & + & & & + & \\
\hline C. kousa & reticulate & + & & + & & + & + & & & + & foveate \\
\hline C. nuttallii & reticulate & + & & & & + & + & & & + & \\
\hline \multicolumn{12}{|c|}{ DW } \\
\hline C. canadensis & \begin{tabular}{|l} 
reticulate \\
\end{tabular} & + & + & & & + & + & & + & & \\
\hline C. suecica & reticulate & + & + & & & + & + & & + & & \\
\hline
\end{tabular}

